\title{
Bioanalysis
}

\section{Antigen arrays for profiling autoantibody repertoires}

\begin{abstract}
Autoantibodies are a key component for the diagnosis, prognosis and monitoring of various diseases. In order to discover novel autoantibody targets, highly multiplexed assays based on antigen arrays hold a great potential and provide possibilities to analyze hundreds of body fluid samples for their reactivity pattern against thousands of antigens in parallel. Here, we provide an overview of the available technologies for producing antigen arrays, highlight some of the technical and methodological considerations and discuss their applications as discovery tools. Together with recent studies utilizing antigen arrays, we give an overview on how the different types of antigen arrays have and will continue to deliver novel insights into autoimmune diseases among several others.
\end{abstract}

First draft submitted: 22 June 2015; Accepted for publication: 16 March 2016;

Published online: 21 April 2016

Keywords: affinity proteomics $\bullet$ antigen microarrays $\bullet$ autoantibodies $\bullet$ autoantibody profiling $\bullet$ autoimmunity $\bullet$ protein biomarker discovery

Detection of circulating autoantibodies holds a great promise to support diagnosis, prediction, classification and monitoring of various diseases. Within rheumatoid arthritis, for instance, the presence of a group of autoantibodies to citrullinated protein antigens is associated with more severe structural damage and poorer response to therapy in RA patients [1]. Furthermore, the presence of this group of autoantibodies among healthy individuals is related to an increased risk of developing RA [2]. There are other examples where evidence suggests that in various diseases autoantibodies are produced in patients several years before the onset of clinical symptoms, thus highlighting the early prediction potential of autoantibody analysis [3,4]. The need for such autoantibody-based biomarkers is escalating in a wide spectrum of diseases, ranging from autoimmune conditions to cancer [5], especially when taking into consideration their potential for stratification of patient groups in relation to outcome of therapies and even for development of antigen-specific therapies [6]. Although the value of autoantibodies as disease biomarkers has been recognized in some conditions [7], it still remains underutilized regarding several other ones, where disease-related target self-antigens are not known yet.

Conventional immunoassays such as ELISA are commonly used in the field of autoimmune laboratory diagnosis, but such strategies are limited to a priori knowledge of the autoantigens, thus not allowing for novel discoveries from a research perspective. Besides, such assays are not able to offer a high-throughput and multiplex analysis of several hundreds of body fluid samples against several hundreds of antigens. In this review, we will describe various aspects of the antigen array technology and different antigen array platforms, which fulfill such a need for profiling body fluid autoantibody repertoires in a high-throughput and highly multiplex manner. In addition, we will also address
Burcu Ayoglu ${ }^{* 1,2}$, Jochen M Schwenk ${ }^{1}$ \& Peter Nilsson' ${ }^{1}$

${ }^{1}$ Affinity Proteomics, SciLifeLab, School of Biotechnology, KTH - Royal Institute of Technology, Stockholm, Sweden ${ }^{2}$ Department of Medicine, Division of Immunology and Rheumatology, Stanford University School of Medicine, Stanford, California, USA

*Author for correspondence: burcu@kth.se 
some aspects, which pose analytical or practical challenges, as well as various methodological and statistical considerations applicable for studies employing antigen arrays as their main discovery tools. Finally, we will give an overview of the attempts made in recent years regarding the application of antigen arrays for autoantibody profiling, mostly geared towards identification of potential biomarker candidates.

\section{Overview of antigen array technologies \& platforms}

\section{Antigen array formats}

Planar arrays

The conceptual foundation for producing an immunoassay in a 'microspot' fashion was introduced in 1960s, where the utility of depositing microspots of an antigen solution was demonstrated for detection of serum autoantibodies against thyroglobulin in autoimmune thyroiditis patients [8]. Two decades later, the theoretical principle of microspot assays was proposed [9]. It was, however, not until 1990s that the contemporary planar, or 'spotted' microarray concept took its current shape when the DNA microarray technology hit its peak and the concept of a simultaneous analysis of several thousand probes spotted on solid supports proved itself as a highly valuable tool within genomics and transcriptomics. In the beginning of 2000s, the ready availability of robotic printing devices and scanners within the DNA microarray world led to the adaptation of equipment and procedures and the pioneering proof-of-concept studies demonstrating the feasibility of 'printing proteins' followed [10,11]. Soon after, the potential of spotted protein microarrays for the analysis of entire proteomes was demonstrated [12].

Planar antigen arrays are generated by immobilization of a large number of different antigens in microspots, generally at a spatial density of up to 2000 per $\mathrm{cm}^{2}$ or more. The capture reagents are immobilized on the solid support by means of either contact printing devices using, for example, pins that touch the surface of the solid support, or noncontact printing devices that involve jetting systems forming and propelling droplets onto the solid surface. Only minute amounts of capture reagent volume are spotted, usually in the range of $50-500 \mathrm{pl}$, resulting in spot sizes of $100-300 \mu \mathrm{m}$ depending on the utilized solid support properties.

A large number of different solid support options are available, offering different surface chemistry choices for planar arrays. As recently reviewed, for example, by Sutandy et al. [13], surface immobilization strategies can in general be categorized as physical, covalent or affinity-based immobilization. Surfaces coated with nitrocellulose or gel pad allow for a passive adsorption resulting in noncovalent and nonspecific attachment of proteins, whereas, for example, epoxyactivated surfaces allow for a covalent attachment of proteins through their accessible amine, hydroxy or thiol groups. Surfaces coated with affinity tags, such as avidin or histidine, allow for an affinity-based, noncovalent but specific attachment of proteins or peptides. While epoxy-activated or nitrocellulose-coated surfaces allow for a random orientation of the proteins, affinity tag coated surfaces allow for a uniform orientation of the proteins. In choosing a slide surface, it is important to consider whether a uniform or a random orientation of the proteins is desired in order not to mask any epitopes.

There is no universal solid support type with a particular surface chemistry, which is suitable for several, let alone all applications. On the contrary, before exploiting the full utility of planar affinity arrays for profiling samples, usually a considerable amount of time has to be spent to develop and find the right surface chemistry and to fine-tune the assay protocols accordingly. Here, several aspects need to be considered, such as whether the printed proteins have to retain their conformation and functional stability without undergoing denaturation. Usually, a similar effort has to be spent for identifying the optimal buffer composition to block the array surface prior to application of samples.

To date, signal generation on planar arrays mostly relies on fluorescence-based methods. This is simply due to the fact that the laser scanners compatible with fluorescent dyes, developed and widely used for DNA microarrays, were directly implemented into the protein microarray field. Such scanners typically provide a fluorophore excitation at wavelengths of 532 and 633 $\mathrm{nm}$, allowing for a detection of organic fluorescent dyes such as Cyanine and Alexa Fluor or protein-pigment complexes such as R-phycoerythrin (R-PE). Although read-out by fluorescence has been and still is by far the most widespread signal generation method within planar (as well as bead-based) array applications, there is indeed a rich spectrum of alternatives. This includes both label-based methods, such as chemiluminescent or nanoparticle labeling as well as label-free methods, such as surface plasmon resonance, carbon nanotubes and microcantilevers. A very comprehensive overview of such emerging signal generation methods, as well as a comparison regarding the detection sensitivities they offer, has been provided by Chandra et al. [14] and Ray et al. [15].

\section{Bead-based arrays}

The principle of bead-based arrays, or the so called suspension bead arrays, relies on immobilization of capture reagents on distinguishable microsphere sets 
as solid supports and detection of the captured targets on each microsphere set by means of a flow cytometric read-out system. Microspheres utilized as solid supports carry functional groups, such as carboxyl or thiol groups, facilitating the immobilization of proteins. Microspheres pre-coupled with neutravidin can also be utilized to immobilize biotin-containing capture reagents, which offers an alternative for immobilization of, for example, synthetic, biotin-containing peptides.

The concept of utilizing microspheres as a solid support is in fact not as new as it is generally anticipated. Almost 40 years ago, the potential use of microspheres for immobilization of antigens to identify antigenspecific antibodies in serum was described [16]. A decade later, McHugh et al. demonstrated this possibility by simultaneously detecting serum antibodies against herpes simplex and cytomegalovirus antigens, which were immobilized on microsphere sets with different diameters [17]. Towards the end of 1990s, embedding spectrally different fluorophores into microspheres to prepare 64 spectrally distinct microsphere populations was demonstrated [18]. This lay the foundation for the multiplex microsphere array technology provided today, for example, by the Luminex Corporation.

This technology is built on the use of polystyrene microsphere sets, which are internally dyed with precise amounts of two or three spectrally different fluorophores. Since each microsphere set can be distinguished by their spectral address, microsphere sets, each linked to a distinct capture reagent can be combined within a single array, allowing for a multiplex measurement. The first generation of these microspheres contained two internal fluorescent dyes allowing for a multiplexing of up to 100 analytes, whereas the next-generation microspheres containing three internal dyes allow for a multiplexing of up to 500 analytes. In addition to commercially available technologies, it is also feasible to develop home-brewed protocols. This was demonstrated by $\mathrm{Wu}$ et al., where maleimide-derivatives of fluorescent dyes were used to generate 1152 different microsphere sets [19].

The flow cytometer-like bead analyzers compatible with 100 -plex or 500 -plex bead arrays offer a throughput of 96 or 384 samples in microtiter plates. In the analyzers, each microsphere is subjected to a $635-\mathrm{nm}$ laser beam, which excites the internal fluorescent dyes in each microsphere and allows for the deconvolution of the spectral address. A 532-nm laser beam excites the reporter molecule bound to the analyte and enables for read-out in terms of median fluorescence intensity (MFI) across each distinct microsphere set.

Microspheres embedded further with superparamagnetic particles allow for an automated plate washing or magnetic bead transfer, which are important aspects contributing for a good recovery of microspheres, a good assay reproducibility, a reduced hands-on time and human error. Both nonmagnetic and magnetic microspheres are functionalized, for example, with carboxyl groups, allowing for covalent immobilization of proteins via their primary amine groups. Besides, there are ready-to-use kits for analysis of autoantibodies, such as antinuclear antibodies (ANAs) [20].

Various studies have evaluated the agreement between measured serum autoantibody levels, such as ANAs [21], or levels of antibodies against viral antigens, for example, from Epstein-Barr virus [22], using ELISA and multiplex bead-based assays and reported concordant performances. Offering less consumption of crude sample volume, less sample processing time and multiplexing capacity while not compromising analytical sensitivity and accuracy makes bead-based arrays highly versatile tools. The open architecture offered by the bead-based arrays offers the possibility to develop and continuously fine-tune home-brewed protocols to create arrays with a fully customized content of proteins or peptides.

\section{Planar arrays versus bead-based arrays}

While practically being restricted solely to the availability of antigens, planar array platform theoretically offers the possibility to spot tens of thousands of antigens within one glass slide for a highly multiplex analysis. This can be considered as the main advantage of planar arrays, suiting the analysis of binding against thousands of antigens at once. Certainly, the more features are spotted on the array surface increasing the multiplexing capacity of the assay, the less possibility to create subarrays, where individual samples can be analyzed on the same array surface, thus a lower sample throughput. Planar array platform can, therefore, be considered as a suitable initial discovery platform suited for identification of potential biomarker candidates by analyzing sample collections in the range of lower hundreds. These can be verified further on technological platforms offering much higher sample throughput capacity, such as the bead-based arrays.

Bead-based arrays offer also certain advantages over planar arrays, including no requirement for laborious image analysis, direct collection of data, greater sample throughput and a more flexible and customizable array content. An array facility to generate and utilize planar arrays would require scanners, image analysis software and sophisticated printing robots which can usually be operated by experienced users, whereas a facility based on bead-based arrays might be established in less time-frames due to the more user-friendly nature of the currently available bead-based technolo- 
gies. However, as indicated before, planar arrays offer a possibility to generate arrays with hundreds to few thousands of proteins or antibodies per $\mathrm{cm}^{2}$, thus theoretically allowing for a greater degree of multiplexing than offered by the most widely used bead-based platforms. These two array platforms indeed complement each other when efficiently utilized at different phases of biomarker discovery studies, as well as when each platform is utilized to technically verify the findings revealed by the other, as demonstrated in our recent study [23].

\section{Antigen array platforms}

Using antigen arrays, both analytical and functional assays can be performed. In a functional assay format, the arrayed antigens are utilized to decipher various binding activities such as protein-protein, proteindrug, protein-peptide or protein-nucleic acid interactions, as reviewed, for example, by Zhu et al. [24] and by Sutandy et al. [13]. In an analytical assay format, arrays of antigens are used to detect and characterize antibodies, either against self- or non-self antigens. Here, we will frame the discussion mainly to the analytical assays for antibody profiling on antigen arrays. Although for this purpose other types of bait reagents, such as lipids or carbohydrates can be utilized as antigens, we will mainly discuss arrays of full-length proteins, or fragments thereof, and arrays of peptides (Figure 1).

\section{Protein arrays}

There are two strategies to fabricate protein arrays: proteins from a recombinant or nonrecombinant source, such as a crude or preseparated protein extract,

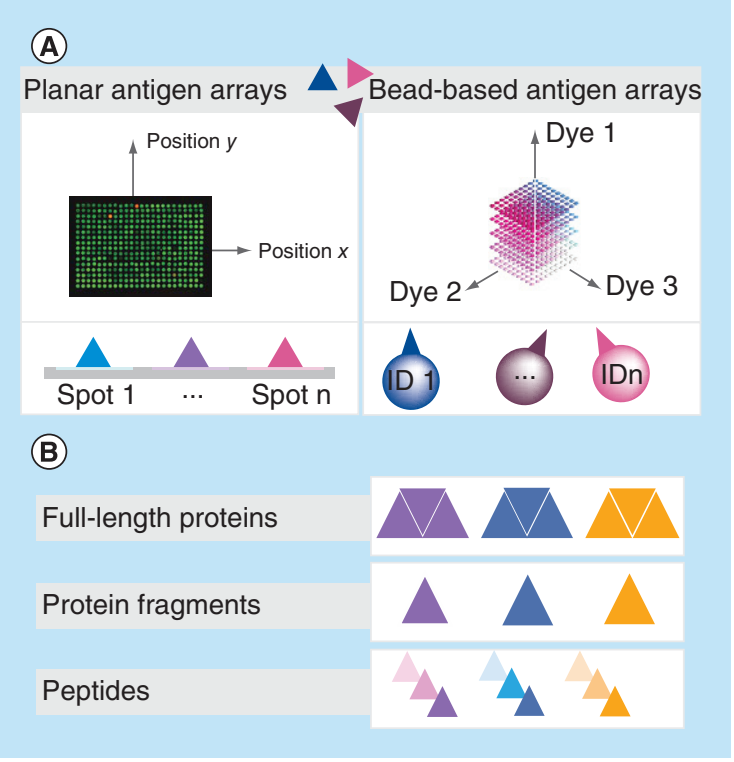

Figure 1. Formats and binder types for antigen arrays. can be either immobilized on planar or bead-based surfaces, or they can be expressed in situ, namely on spot (or on bead) using cell-free expression systems.

\section{Protein arrays by in situ synthesis}

The in situ array production strategy eliminates the need to separately express and immobilize the proteins and relies on the synthesis of proteins directly on the array in a cell-free manner. Here, DNA templates, either in the form of a plasmid or a PCR product are utilized. The DNA template allows for protein synthesis in the presence of a crude cell lysate, which contains all macromolecular components needed for the transcription and translation machineries, such as ribosomes and initiation, elongation and termination factors. These components are also supplemented with, for example, amino acids, salts and cofactors. Cell-free protein expression systems were traditionally made from E. coli, followed later by cells from eukaryotic species, such as wheat germ cells, insect cells or rabbit reticulocyte, as reviewed, for example, by $\mathrm{He}$ et al. [25] and Carlson et al. [26].

Within the last decade, several in situ protein array production strategies emerged upon the marriage between such commercially available cell-free protein synthesis methods and the protein array technology. A prototype strategy, the so-called protein in situ array (PISA), later also known as DiscernArray ${ }^{\mathrm{TM}}{ }_{\text {[27] }}$, was originally described by $\mathrm{He}$ and Taussig [28]. In PISA, PCR-generated DNA constructs are designed to encode a protein or a fragment thereof, and a tag sequence. The array surface is precoated with a tag capture agent and after translation using a cell lysate, the synthesized proteins are captured on the array surface and the unbound lysate material is washed off. Angenendt et al. later miniaturized PISA further by utilizing a multiple spotting technique increasing the theoretical spot density up to 13,000 [29].

An alternative to PISA, the so-called nucleic acid programmable protein array (NAPPA), was originally described by Ramachandran et al. [30]. The concept of NAPPA is based on spotting the DNA template, in this case a biotinylated plasmid, encoding the protein of interest as a fusion with a GST tag. The array surface is precoated with avidin, as well as an antibody targeting the GST tag. Upon incubation of the spotted plasmid DNA array with the cell lysate, the expressed protein is captured within each spot by the antibody against tag. A next version of NAPPA was described [31], where planar arrays consisting of up to 1000 proteins were generated and later Wong et al. adapted the NAPPA strategy on bead-based arrays [32]. One of the important concepts offered by the NAPPA strategy is the feasibility of storing an array with the DNA template 
for a long term until usage. In turn, the protein spots (or beads) are per se not 'pure' since they remain colocalized with the DNA template and the antibody against the tag.

A third in situ protein array production strategy, the so-called DNA array to protein array (DAPA) was originally described by $\mathrm{He}$ et al. [33] and recently optimized further [34]. The concept behind DAPA involves two slides and a permeable membrane in between: one slide is immobilized with PCR-generated DNA constructs encoding tagged proteins, the other slide is immobilized with tag-capturing reagents, and between the two slides the cell-free protein synthesis is carried out within a filter membrane. The newly synthesized proteins on the first slide diffuse through the membrane and become captured on the second slide. The main advantage offered by the DAPA strategy is the possibility to reuse the same DNA array up to 20 times to generate multiple copies of a protein array [33]. In comparison to NAPPA, DAPA also allows to generate 'pure' protein spots on a separate surface than the DNA template. Yet, diffusion can be regarded as a potential limitation to synthesize multimeric proteins. Besides, the protein spots occupy a large area due to diffusion effects; the so far reported spot densities for DAPA strategy have been in the range of 100 [35].

Taken together, the in situ array production strategies in principle avoid the need to express, purify and store individual proteins, thus also reduce the concerns about the storage stability of protein arrays. When a mammalian cell-free protein synthesis systems, such as rabbit reticulocyte lysate, is utilized, in situ array platforms also enable the expression of full length eukaryotic proteins with native protein conformation.

\section{Protein arrays by printing}

The more conventional approach of fabricating protein arrays is based on immobilization of proteins on a solid support. where the source of the proteins can be nonrecombinant, such as a crude or preseparated protein extract from a cell line or tissue [36], or a recombinant source. While the latter strategy, namely the expression and purification of proteins individually is a challenging task in several aspects, the feasibility of fabricating arrays with thousands of proteins have been demonstrated by the earliest pioneering studies in the field: Zhu et al. demonstrated the feasibility of fabricating an array containing approximately $80 \%$ of the yeast proteome by cloning, expressing and purifying almost 6000 yeast open reading frames as GST-His6 fusion proteins [12]. Using the same strategy, Chen et al. demonstrated the feasibility of fabricating an array with over 4200 E. coli proteins, representing $99.3 \%$ of the E. coli genome [37]. This approach originally described by Zhu et al. was commercialized by Proteometrix Inc., subsequently acquired by Invitrogen ${ }^{\mathrm{TM}}$ (now Thermo Fisher Scientific), which is using GST fusion proteins in its ProtoArray ${ }^{\circledR}$ product line. The current 5.0 version of the ProtoArray ${ }^{\circledR}$ Human Protein Microarray hosts over 9000 full-length human proteins expressed in insect cells. Similarly, in one of the early protein array studies, Lueking et al. fabricated arrays with 2,413 fulllength human proteins expressed in $E$. coli utilizing a human fetal brain cDNA expression library [38]. This approach was later commercialized as the UNIarray ${ }^{\circledR}$ platform by Protagen Diagnostics.

More recently, Jeong et al. reported an array with 16,368 human open reading frames as GST-His6 fusion proteins expressed in yeast, representing 12,586 unique genes, thus $60 \%$ of the human protein-coding genes [39]. This framework was recently commercialized by CDI Laboratories as the HuProt ${ }^{\mathrm{TM}}$ Human Proteome Microarray, containing 19,394 full-length human proteins in its version 2.0 and corresponding to over $75 \%$ of the human protein-coding genes.

The recombinant human protein fragments generated within the Human Protein Atlas [40] represent yet another approach, demonstrating the feasibility of large-scale expression and purification of human antigens. Currently, the Human Protein Atlas hosts over 41,000 MS-verified human protein fragments, representing more than 18,000 human protein-coding genes. These 50-150 amino acid long fragments are expressed in $E$. coli as recombinant fusion human protein fragments, which are subsequently utilized within the Human Protein Atlas pipeline to generate planar antigen arrays. These arrays consist of random sets of 384 human protein fragments and are routinely utilized to characterize the binding specificity of newly generated Human Protein Atlas antibodies [41]. The collection of these protein fragment arrays offers a valuable protein array resource. More recently, protein fragment arrays with a larger content have been fabricated as well, which host 21,120 human protein fragments and representing 12,412 protein encoding genes [42] and we are currently in the process of producing a next generation of these arrays hosting 41,393 protein fragments and representing 18,191 protein encoding genes.

\section{Peptide arrays}

In addition to proteins or protein fragments, antigen arrays can be generated by utilizing synthetic peptides. Peptide arrays are very efficient tools for the characterization of epitopes of autoantibodies that have been identified using protein array platforms, at a single amino acid resolution. The main disadvantage of synthetic peptides compared to full-length proteins or 
protein fragments is that they are restricted to mimic discontinuous epitopes and allow to assess continuous epitopes. Yet, peptides offer certain advantages such as they might be relatively inexpensive to synthesize; they are physically and chemically more stable than proteins thus offer more stability during storage and they offer incorporation of certain posttranslational modifications such as citrullination or phosphorylation. Similarly, they allow for incorporation of non-natural amino acids and other modifications for detection or immobilization, such as biotin or a histidine tag, which can be introduced at any required position.

Peptide arrays might be considered to designate the emergence of the array technology. The foundations for peptide arrays were laid in the 1960s when the concept of solid phase peptide synthesis and automated peptide synthesizers emerged. Adopting these concepts, Geysen $e t$ al. introduced the early version of peptide arrays [43]. Shortly thereafter, the so-called SPOTTM synthesis approach was introduced [44], which demonstrated the possibility of in situ synthesis of peptides. The principle of SPOT ${ }^{\mathrm{TM}}$, applied in a further miniaturized way, is still utilized in currently available commercial peptide array platforms such as PepSpot ${ }^{\mathrm{TM}}$ or PepStar ${ }^{\mathrm{TM}}$ provided by JPT Peptide Technologies.

Around the same time as the emergence of the SPOT ${ }^{\mathrm{TM}}$ approach, Fodor et al. reported another breakthrough in situ approach by combining the solid phase peptide synthesis concept with semiconductor fabrication concept [45]. Here, peptide arrays were generated on glass slides using combinatorial synthesis based on photolithography. This method relied on synthesis of peptides by repeated cycles of coupling of activated amino acids and photodeprotection with a photomask. This strategy was in fact adopted for photolithographic synthesis of high-density oligonucleotide arrays [46]. Regarding the synthesis of peptides, requirements such as individual synthesis of amino acid monomers with photolabile protection groups led to further modifications of the photolithographic approach. For instance, Singh-Gasson et al. [47] replaced the photomasks with digital micromirrors, which has been adopted also in more recent studies, such as by Shin et al. [48] and by Buus et al. [49]. A similar approach to the one described by Buus et al. was recently utilized by Roche NimbleGen Inc. to fabricate an array with 2.1 million overlapping peptides representing all human protein coding-genes [50].

Mask-free photolithographic methods have been also developed such as by Gao et al. [51] and by Price et al. [52], where the latter work demonstrated the feasibility and utility of peptide arrays using microprocessor-grade silicon wafers as solid support. In addition to these strategies, particle-based peptide array fabri- cation methods have been introduced. Relying on the basic principle of SPOT ${ }^{\mathrm{TM}}$, Beyer et al. developed a combinatorial synthesis method utilizing electrically charged amino acid particles positioned on a solid support by electrical field which is generated either by a computer chip [53] or a laser printer [54]. This technology is currently commercialized by PEPperPRINT, providing PEPperCHIP ${ }^{\circledR}$ Peptide Microarrays.

The methods outlined so far exemplify the in situ peptide array synthesis approaches and a more detailed overview has been provided, for example, by Katz et al. [55]. These approaches currently allow to generate high or even ultrahigh density peptide arrays. Certainly, it is also possible to fabricate peptide arrays by immobilizing presynthesized peptides. This approach is more suited to generate arrays with a more limited content geared towards more focused investigations. It also allows to utilize peptides upon assessment of their identity and purity, which is not feasible when generating peptide arrays in situ.

\section{Technical considerations relevant for antigen arrays}

Type \& source of antigens

One of the most important considerations for antigen array applications is the type and source of the antigens. Bacterial expression systems, such as E. coli are extensively used and optimized for production of human proteins or fragments thereof, as also demonstrated within the Human Protein Atlas. However, eukaryotic expression systems are needed when aspects such as posttranslational modifications, native folding and activity need to be addressed. Certainly, the consideration regarding the type of expression system applies also when in situ array production strategies are adopted. Important to note is that folding and activity of proteins expressed in eukaryotic systems might still be compromised by adsorption or covalent attachment of the proteins to the surface of utilized solid support, which highlights the importance of testing different array surfaces and related parameters for downstream applications such as autoantibody profiling [56]. Such changes in antigen structure might affect discontinuous epitopes that might be of relevance, but it can also expose epitopes that otherwise are not accessible to antibodies as recently underlined by Wang et al. [57]. Thus, there is no established ultimate strategy in terms of the type and source of the employed antigens, which can be utilized to explore the diversity of the autoantibody repertoire. There are studies demonstrating not only the value of employing full-length proteins expressed in eukaryotic systems, but also the value of recombinant protein fragments [23], synthetic overlapping peptides [52] or even random-sequence pep- 
tides [58,59] or peptidomimetics [60], each with their inherent advantages and disadvantages. Even antibody arrays can be used to study in particular those autoantigens circulating in complex with their autoantibodies [61]. Thus, initial discoveries made with a given type of antigen can be reevaluated and verified using antigens of alternative types and sources.

\section{What to detect?}

As highlighted by Prechl et al. [62], for antigen array applications aiming to profile the autoantibody repertoire in body fluids, the consideration regarding what to detect is as important as what to immobilize as antigens. A majority of autoantibody profiling investigations focus to determine antigens recognized by autoreactive IgG antibodies only (Figure 2). Yet, the feasibility and potential value of detecting subclasses of $\operatorname{IgG}[63,64]$ or different immunoglobulin classes on antigen arrays have been demonstrated $[65,66]$. While these and similar investigations utilized planar arrays, a study by Ayoglu et al. aimed to develop a bead-based assay allowing for a parallel analysis of antibodies of $\operatorname{IgG}, \operatorname{IgM}$ and $\operatorname{IgA}$ classes [67]. In addition to the analysis of class or subclass distribution, examination of the clonality of the autoantibodies by using kappa or lambda light chain specific detection antibodies might reveal highly relevant information in the context of various conditions if an altered light chain kappa/lambda ratio is hypothesized to be disease or disease-stage associated [68] (Figure 3).

The specificity of the secondary detection antibody might be an important factor to consider when analyzing only a single autoantibody class. For instance, regarding the choice for secondary reagents to detect IgG autoantibodies, reagents with specificity against both heavy and light chain or with specificity against only the Fc portion of the heavy chain can be utilized. Reagents specific against both heavy and light chain might offer a broader epitope recognition than Fc fragment-specific reagents, but they might react with other immunoglobulin classes since they share the same light chain. Depending on the quality of the reagent, Fc fragment-specific secondary antibodies might still cross-react with other immunoglobulin classes. Thus, either highly optimized secondary reagents should be preferred or secondary reagents from different vendors with different specificities should be evaluated before any a large-scale analysis of clinical samples.

As reported in a recent work [67], when serum samples are screened at a low dilution rate, captured serum immunoglobulins building an antigen-antibody complex on the array surface might activate the complement system, which might in turn mask the detectability of captured immunoglobulins by secondary reagents. Thus, prior to any large-scale analysis of serum samples, it might be beneficial to evaluate different sample dilution rates and the need to block the complement system by means of suitable assay buffer additives such as EDTA.

Antigen array-based autoantibody profiling approaches using planar arrays mostly adopt a singlecolor approach, where autoantibodies are detected using fluorescent dye labeled secondary antibodies. Dual-color approaches have also been described for array-based autoantibody profiling approaches. Hartmann et al. utilized a dual-color approach for detection of both total immunoglobulin and antigen-specific autoantibodies [69]. Kattah et al. described the co-incubation of two different samples labeled with fluorescent dye-labeled Fab fragments [70]. Approaches like the latter might allow to incorporate a reference sample for internal normalization, which can be a preferable strategy when analyzing, for instance, longitudinal sample collections. As shown in our previous work using tagged protein fragments as antigens [23], a dual-color approach can also be used to involve a secondary antibody to detect the tag and this information can in turn be utilized both for spot alignment and for normalization.

\section{Other technical aspects}

Prior to autoantibody profiling applications, purification of immunoglobulins by means of protein A/G can be considered as a strategy to enrich for immunoglobulins in body fluid samples. Yet, systematic evaluations addressing the effect of such preanalytical steps on array-based downstream analyses have so far not been reported in detail.

Upon identification of targets on autoantibodies, competition assays can add valuable information regarding the degree of autoantibody specificity. Here, an assessment of the reduction in antibody binding upon preblocking of samples with the identified target would provide support for autoantibody specificity. This can be an especially important point when proteins or protein fragments are expressed as fusion proteins in bacterial expression systems, since body fluid samples from a subset of individuals might contain antibodies reacting, for example, with the expression tag. In such cases, depending on the antigen type and source, a protocol step for preblocking of samples with the expression tag or a lysate originating from the expression system should ideally be evaluated prior to analysis of large sample collections [23].

A similar consideration is relevant when utilizing peptide arrays for autoantibody profiling purposes. In several applications, peptides are generated with a C- or N-terminal biotin and a linker molecule, which 


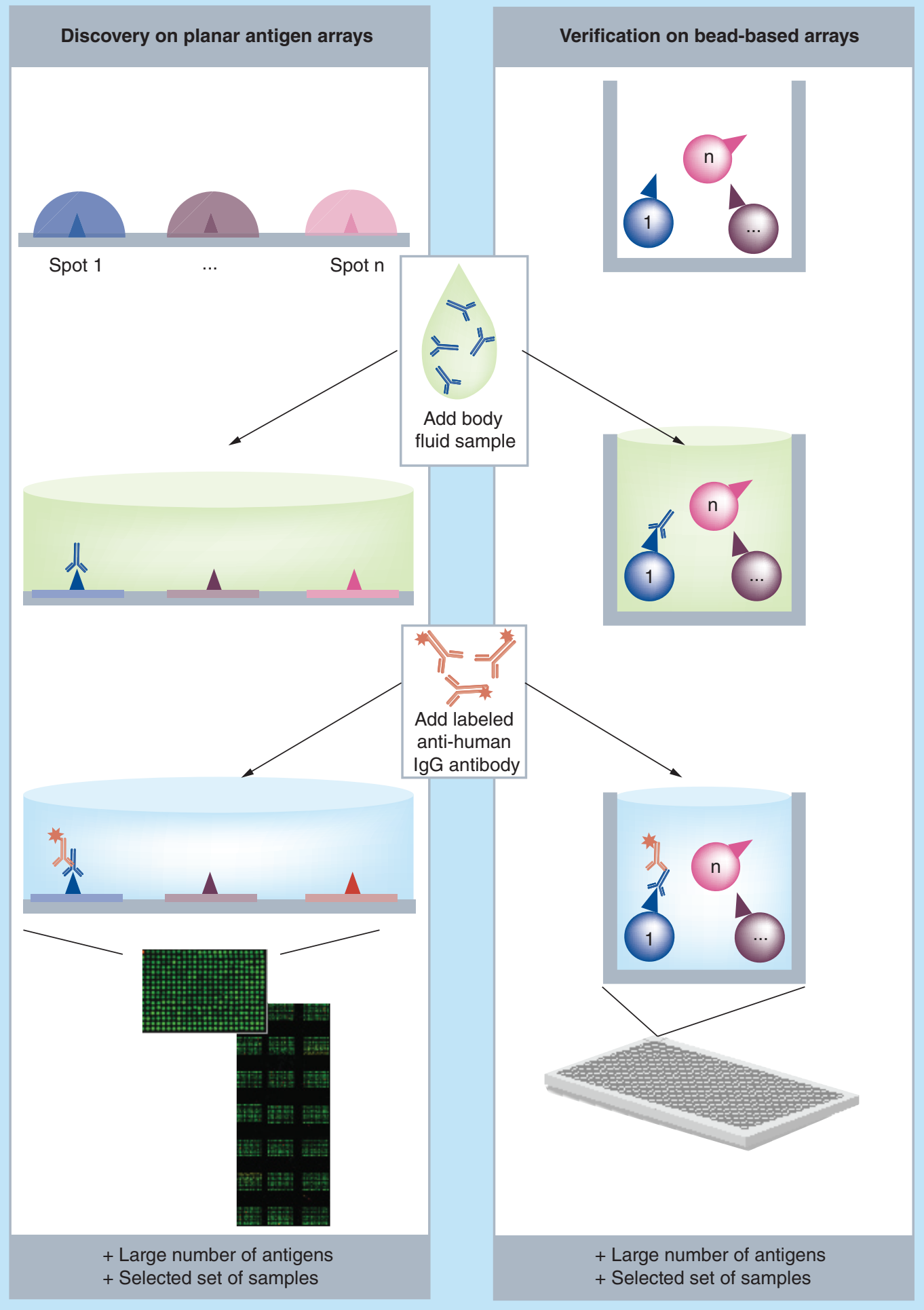

Figure 2. A typical autoantibody profiling assay workflow on planar or bead-based antigen arrays.

allow to immobilize peptides on, for example, neutravidin-coated planar or bead-based surfaces. Yet, as reported in our previous work [67], body fluid samples from a subset of individuals might contain antibodies reacting with neutravidin, which might require a step for preblocking of samples. 

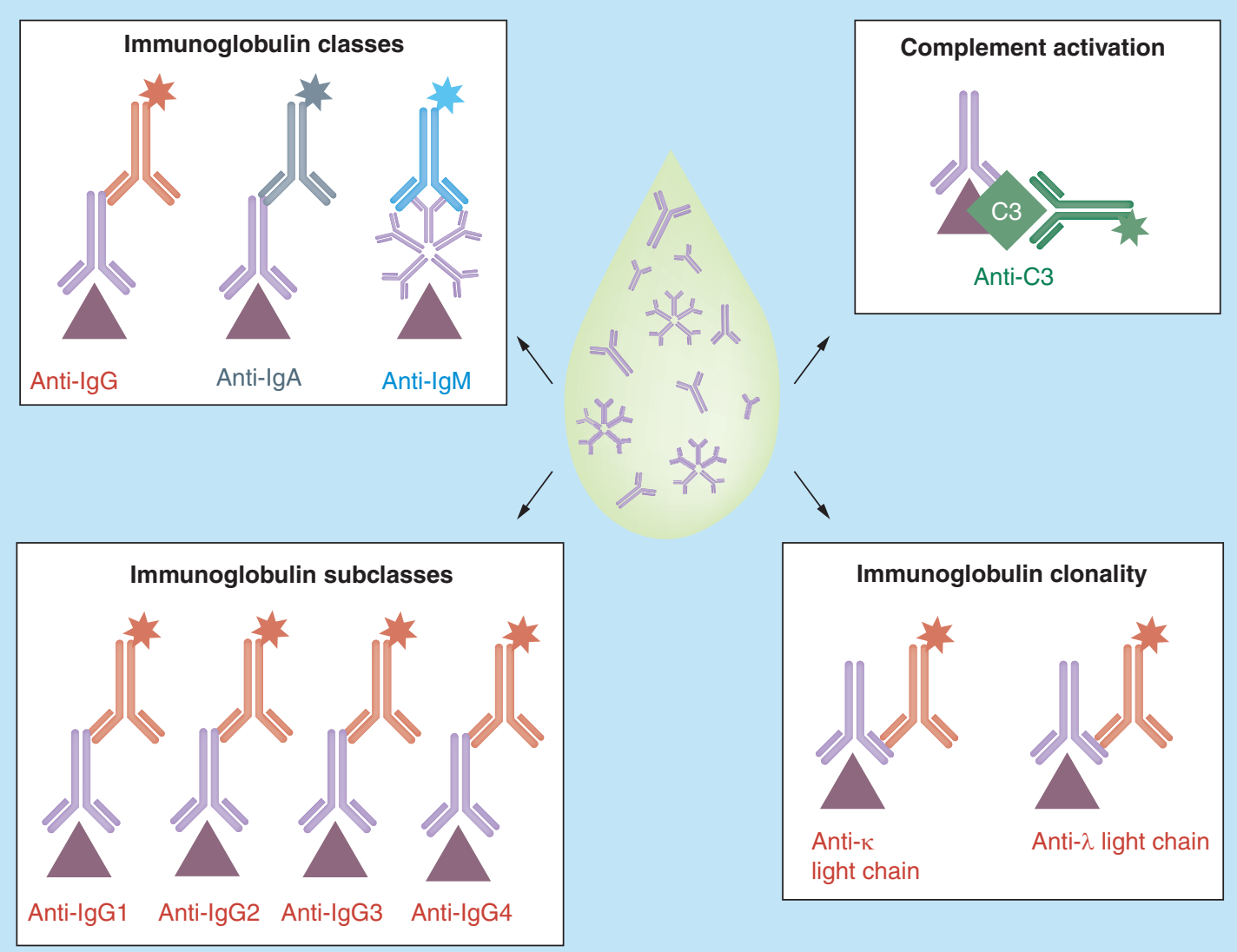

Figure 3. Strategies for detection of autoantibodies on antigen arrays providing different levels of information.

\section{Experimental, statistical \& methodological aspects}

In this section, we would like to reflect on miscellaneous general aspects regarding study design for biomarker discovery-oriented assays carried out on antigen arrays. We also would like to share some common practices regarding experimental design and data and statistical analysis.

\section{About study design: from samples to assays}

For a study aiming to identify differentially abundant autoantibodies as a potential biomarker candidate for a certain disease, the choice of control samples is of utmost importance. While several population-based control samples can be accessed easier from a population register, hospital controls, especially those with other diseases, might represent a more relevant population, although they might not provide an unbiased representation of a control group. Thus, it should be evaluated in close collaboration with experts of the studied disease, whether population controls or hospital controls are more suitable for the intended study outcome.

Control samples should ideally be matched in terms of demographic variables such as age and gender, if not for other relevant variables as well. However, this might be difficult for some diseases, for example, if the sample type is an invasively collected body fluid or if the patients are very young. Similarly, when several disease subtypes are compared, matching subtype samples in terms of age can be a challenge since samples belonging to more advanced stages of the disease might per se be older. Finally, possibilities to involve well-selected sample collections of a related disease or of another control set might be worth to consider, as well as sample collections from different centers [71], especially if this can be allowed by the sample throughput of the utilized array platform.

While there are strategies to statistically determine the theoretically required number of samples per group, such as by the statistical power analysis [72,73], analysis of as many samples as the utilized array platform allows for would increase the chances for finding candidates that can be verified downstream. However, as recently also highlighted by Wallstrom et al. [74], statistical expertise should indeed be involved at the early stage of such studies. As expressed by Ronald Fisher, 'to call in the statistician after the experiment is done may be no more than asking him to perform a post- 
mortem examination: he may be able to say what the experiment died of.'

If a subset of samples needs to be selected from a larger sample collection to meet the sample throughput capacity of the array platform, this selection needs to be carried out in close collaboration with experts of the disease in order to determine which disease subtypes or age groups might be prioritized in an initial discovery analysis. Certainly, the sample preparation type and condition should meet the requirements of the technical analysis to be carried out. For instance, serum and not plasma samples, which have not been exposed to freeze-thaw cycles prior to analysis are the suitable sample types for measurement of complement activation on antigen bead arrays [67].

Conventional autoantibody profiling studies on antigen arrays very often employ a targeted approach for antigen selection. This involves selection of a limited set of antigens upon literature mining, where existing knowledge, such as relation to affected tissue, organ, cellular pathways associated with the disease can be taken into consideration. However, as we also previously argued for [75], the increasing availability of antigen collections such as by the Human Protein Atlas, as well as commercially available protein and peptide array formats, allow for the adoption of nontargeted, unbiased approaches for autoantibody profiling on antigen arrays. Thus, antigen arrays can also be implemented within a true discovery framework.

\section{About experimental \& assay design: from assays to data points}

Basic but effective experimental design elements can help to estimate, isolate and eliminate possible bias in autoantibody profiling experiments on antigen arrays. Randomization and replication are for instance, two very basic but very crucial concepts. Randomization of samples protects against introduction of bias, which might be introduced by uncontrollable assayor instrument-related factors. Especially if assays will be carried out on multiple slides or microtiter plates, samples can be applied in a randomized layout, where even a balanced distribution across age, gender and diagnosis type of samples can be applied by a stratified randomization.

Replicating entire experiments can reveal day-today, namely inter-assay reproducibility and including replicates of, for example, both sample-free assay buffer and a sample pool, distributed within and across several slides or microtiter plates can reveal intra-assay reproducibility. Utilizing the same sample pool as a replicate in segmented experiments carried out as different batches can reveal the so-called batch effects [76], which can be addressed during data processing.
Regardless of the robustness of a given assay protocol, relevant positive and negative control analytes need to be included in each assay. Similarly, depending on the type of antigens or samples utilized, even wellestablished buffer compositions should preferentially be fine-tuned. Regarding the content of the antigen arrays, including more than one antigen representing different regions of each target might provide a better insight. However, this is certainly restricted by the multiplexing capacity of the array format utilized and the availability of the antigens.

Finally, it is beneficial to adapt assay protocols to be compatible with automated liquid handling devices, which are becoming increasingly available and affordable. Aliquoting and randomization of samples and/ or antigens should preferably be carried out on such devices in order to reduce hands-on time and risk of human error. Reducing or eliminating hands-on time as much as possible during assays is also an important aspect for a robust outcome especially within large-scale profiling studies on several samples and/or for several targets, where experiments might be carried out by different operators at different days.

\section{About data analysis \& statistics: from data points to potential biomarker candidates}

Data processing and analysis usually gets less attention than the aspects regarding study and experimental design. Ironically, this stage of especially large-scale studies can require equal, if not even more amount of time and effort as generating the data itself. Although the discussion about data analysis and statistical tools applied for antigen array data would be complex enough to write a separate review article, we will briefly summarize some basic aspects.

While the assay read-out for bead-based arrays can be obtained directly from the analytical instrument, there is an intermediate image analysis phase in order to obtain assay read-out for planar array formats. Depending on the number of samples analyzed, the image analysis phase can be very labor-intensive. It ideally requires a visual inspection of the entire topography of each array surface in order to identify and exclude array features affected, for example, by dust specks or scratches before overlaying a grid and extracting the read-out from an image analysis software.

Once data are obtained, there are basic inspections helping to assess the quality of data, such as calculation of coefficient of variation (CV) values for the technical replicates or visualization of data distribution in histograms. The latter implies whether data points should be transformed (e.g., by logarithmic transformation) if common statistical methods making assumptions on normal distribution will be applied. As discussed, for 
example, by van den Berg et al. [77], there are no universally applicable strategies for data transformation, scaling and normalization. In order to identify the most suitable one, different strategies and their combinations might need to be evaluated in each study having its unique composition of sample collection and its own research question. Here, the suitability of each strategy can be evaluated, for example, by their impact on technical CV values.

Before applying statistical methods on the data for comparative analyses, it is a preferred practice to investigate the presence of any systematic variation in the dataset, which might not be disease but sample-related or might have been introduced during the experimental procedure. Here, principal component analysis and unsupervised hierarchical clustering are two useful tools to asses, for example, the presence of sample type, sample batch or sample origin effects. Such analyses can also identify possible artifacts introduced during experimental procedure, such as position effects within a microtiter plate or on a slide. These analysis tools furthermore allow to decipher outliers in the dataset, which might be necessary to be excluded before further statistical analysis [78,79].

Prior to any comparative analysis, it is also important to assess whether there is any systematic variation between case and control groups. Such variation might either be introduced due to differences in the preanalytical chain of sample collection and storage, or it might also reflect a true biological difference in the overall protein content of case and control groups due to disease pathology. Such skewed trends can be reflected by the presence of systematically positive or negative fold changes.

In biomarker discovery-oriented applications, the ultimate aim is to identify the 'features,' namely the antigens, which reveal differences between the compared sample groups. The identified features should be statistically validated using either the available dataset, or preferably a dataset generated using a new sample collection. The feature selection methods utilized for this aim can be divided into univariate and multivariate methods [80]. For a univariate feature selection from data generated on antigen arrays, the nonparametric Wilcoxon rank sum test (or the Kruskal-Wallis test for a multigroup comparison) can be applied. Here, the median for a feature is considered to differ significantly when the hypothesis testing statistics is smaller than the set value for alpha, which is generally set to alpha $=0.01$. The data generated using multiplex arrays is though mostly high-dimensional, namely, not one but as many hypothesis tests are performed as the number of targets. This increases the probability of committing a type I error, namely a false positive error. To address this, multiple testing correction methods can be applied.

For a univariate feature selection, comparison of autoantibody reactivity frequencies within the sample groups can be equally, if not more, insightful. Here, first thresholds need to be defined for 'positive reactivity,' which can be set in a sample-specific, target-specific or control group-specific manner (Figure 4). Once the positive reactivity frequencies are calculated within each sample group, then the nonparametric $\chi^{2}$ test, or preferably a Fisher's exact test suitable also for sample group sizes smaller than 20 , can be applied upon crosstabulation of the frequency information.

It is also possible to utilize a multivariate feature selection strategy, which usually works in concert with a classification method. There are several classification methods, such as partial least squares discriminant analysis (PLS-DA); support vector machines; logistic regression; classification trees and ensemble classifiers such as random forest. Once features have been selected either using a univariate or a multivariate strategy, their performance can be estimated by a cross-validation, ideally using new samples. Alternatively, the dataset can be split into training set and test set parts and methods such as leave-one-out or k-fold cross-validation can be utilized to asses the performance of a classifier. The performance measure of a classifier is given by its diagnostic sensitivity and diagnostic specificity, which are usually plotted together in receiver operating characteristic curve (ROC) and the performance is reported by the area under the curve (AUC). An extended discussion regarding various data analysis tools and strategies relevant for clinical proteomics has been provided by Smit et al. [81]. It should be highlighted that each dataset generated within the context of a certain disease has different characteristics and there is no universal data analysis strategy applicable within all studies.

The identified features as outcome of a nontargeted investigation, can be subjected further for a biological interpretation. Here, functional annotation tools such as DAVID [82] can be utilized to assess whether there are gene ontology (GO) terms significantly enriched for certain molecular functions, biological processes and cellular compartments. Furthermore, use of tools such as STRING [83] can reveal whether the identified set of features contains known protein-protein interaction partners. Integration of such sources of information might provide additional insights about the potential and relevance of the identified biomarker candidates.

\section{From potential biomarker candidates to biomarkers}

As summarized in Figure 5, upon identification of potential targets as outcome of an initial discovery on 


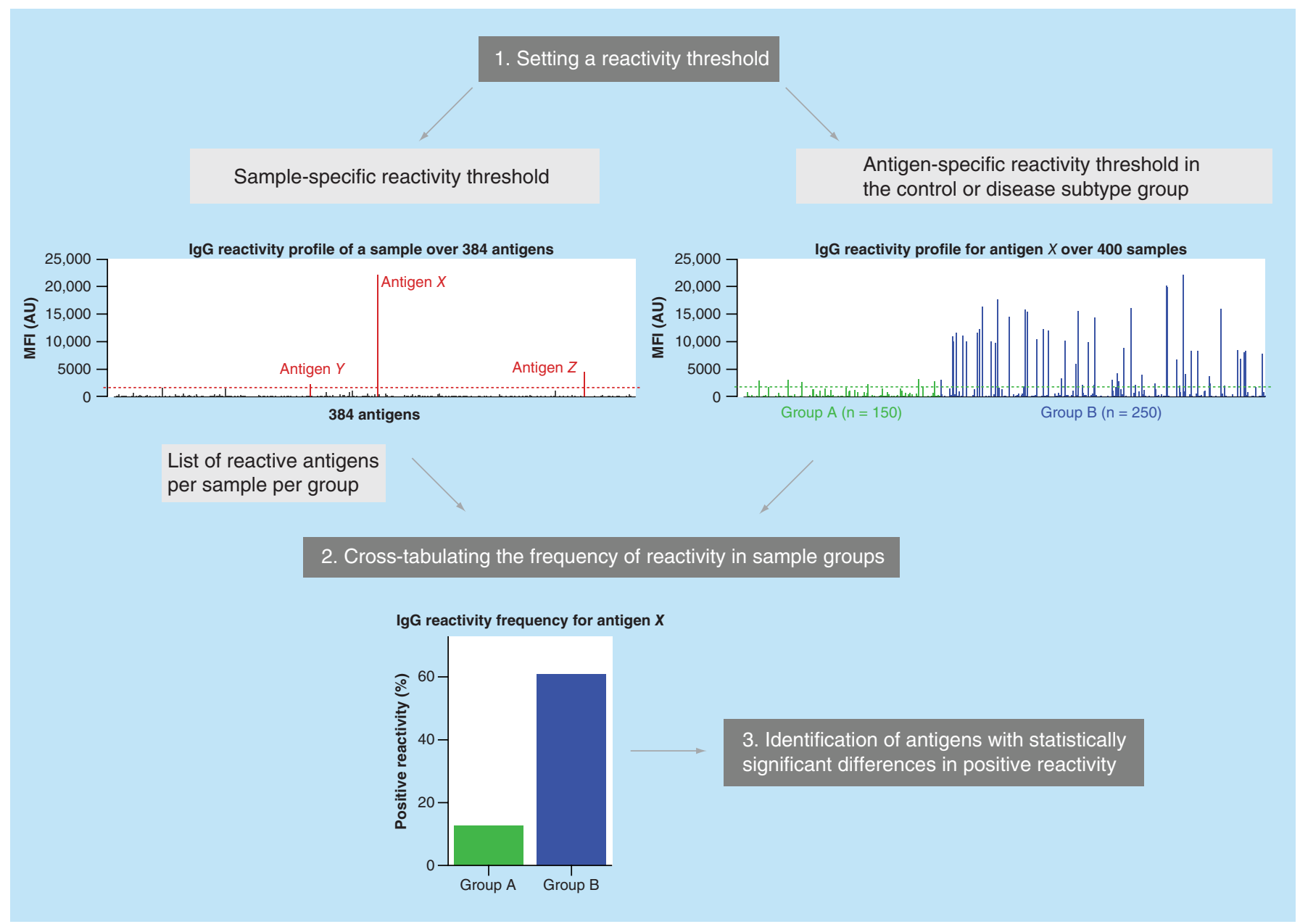

Figure 4. Exemplary data analysis strategy for identification of antigens with differential autoantibody reactivity profiles.

antigen arrays, extensive technical verification steps should be taken to minimize the risk of false positive findings. Here, reproducibility of the study outcome should be confirmed within and across multiple experiments and preferably using an orthogonal technical platform, such as ELISA. As an initial step, different array platforms, namely bead-based or planar arrays can be utilized (Figure $2 \& 6$ ), which can be followed by performing ELISA.

As the next approach, either protein fragments or peptides representing different parts of the target antigen can be utilized to gain better understanding of the binding site of autoantibodies. For initial discoveries made using protein fragments or peptides, an intuitive first step should be to assess whether such autoantibody reactivity patterns are reproduced for a full-length representation of the target protein. It needs to be considered though that producing the full-length version of certain types of proteins, such as transmembrane proteins, might render a challenge.

A technical verification stage should be followed by a 'biological' verification stage. The main purpose of the biological verification stage is to demonstrate the validity of the initially identified autoantibody profiles in new sample collections with same characteristics as the discovery sample set using an orthogonal platform. This should be followed by analysis of new, larger and independent sample collections from different geographical locations. At this stage, the diagnostic specificity and sensitivity of the initially identified set of targets should be assessed, as well as the positive predictive value and negative predictive value. The latter are measures combining the prevalence characteristics of the given disease with the diagnostic sensitivity and specificity [84].

If successfully accomplished, the steps we described so far, starting with a single or a small set of potential biomarker candidates would lead to technically and biologically verified biomarker candidates. At this stage, the intended use of the biomarker candidates should be clarified further and the degree to which the use of these new biomarker candidates would lead for an improved diagnosis or monitoring should be clear. However, this stage of the biomarker discovery pipe- 


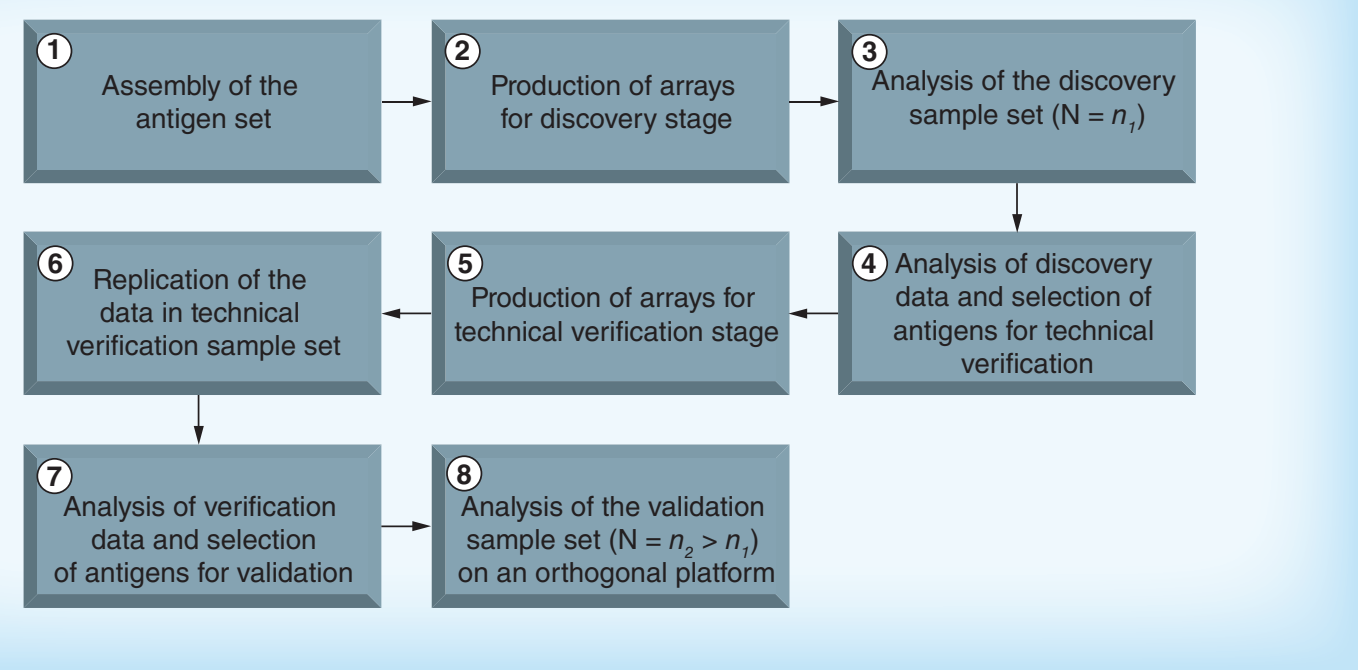

Figure 5. Overview of typical steps of studies using antigen arrays as a platform for discovery of autoantibody targets in body fluids.

line is also when commercial partners with resources and diagnostic expertise might need to be involved, because access to thousands of samples for design and logistics of extensive studies calls for a considerable amount of human and financial resource. Certainly, the decision making criteria for commercial partners closely, if not solely, depends on factors such as a foreseeable and reasonable return on their investment. Thus, a biomarker candidate is still several steps far from becoming a biomarker. Indeed, this perspective strongly argues for the strategy we described above, which integrates the discovery and a characterization of potential biomarker candidates as part of a thorough preclinical discovery process.

\section{Applications of antigen arrays for biomarker discovery}

Antigen arrays offer a multiplex and high-throughput analysis tool for the investigation of the immune response in the context of several conditions. Arrays of allergen extracts [85] or recombinant allergens [86] can be utilized to characterize the immune response in allergy. Similarly, as reviewed by Vigil et al. [87] and Natesan et al. [88] and exemplified in several works [89-92] among others, antigen arrays of pathogens can be utilized to characterize the immune response within various infectious diseases, which might help to develop vaccines or monitor vaccine immunogenicity. By utilizing antigens representing human proteins or peptides, autoimmune reactions against self-antigens can be studied in the context of several diseases, including autoimmune diseases and cancer. In the following section we will mainly focus on this application area of antigen arrays.
Early demonstrations of the utility of antigen arrays for autoantibody profiling approaches were reported by Joos et al. [93] and by Robinson et al. [94]. Joos et al. generated arrays with 18 recombinant proteins well-known to be targets of autoantibodies in autoimmune diseases such as Sjögren's syndrome or rheumatoid arthritis and demonstrated autoantibody binding in serum samples. Similarly, Robinson et al. created arrays with 1152 features representing 196 different well-known autoimmune targets including peptides, proteins and other molecules, which were analyzed with serum samples from patients with autoimmune rheumatic diseases. Joos et al. observed detection sensitivities comparable to ELISA and Robinson et al. reported four- to eight-fold improved analytical sensitivity than ELISA.

Following these pioneering demonstrations of autoantibody profiling applications and reviews highlighting their potential [95-98], antigen arrays have been used in several targeted studies, where selected sets of proteins or both proteins and peptides were utilized to generate antigen arrays: Feng et al. [99] and Hueber et al. [100] investigated rheumatoid diseases; Fattal et al. [101], Li et al. [102], Price et al. [103] and Haddon et al. [104] investigated systemic lupus erythematosus and Balboni et al. [105] investigated juvenile dermatomyositis. Quintana et al. [106,107] analyzed serum and paired serum-cerebrospinal fluid samples in the context of multiple sclerosis. Besides these autoimmune conditions, Britschgi et al. [108] utilized peptide-based antigen arrays within Alzheimer's disease; Gnjatic et al. [109] applied antigen arrays within non-small-cell lung cancer and Hagedorn et al. [65] investigated serum samples from patients with chronic rejection of lung transplantation. These and similar tar- 
(A)

$\lg G$ reactivity profile of a plasma sample

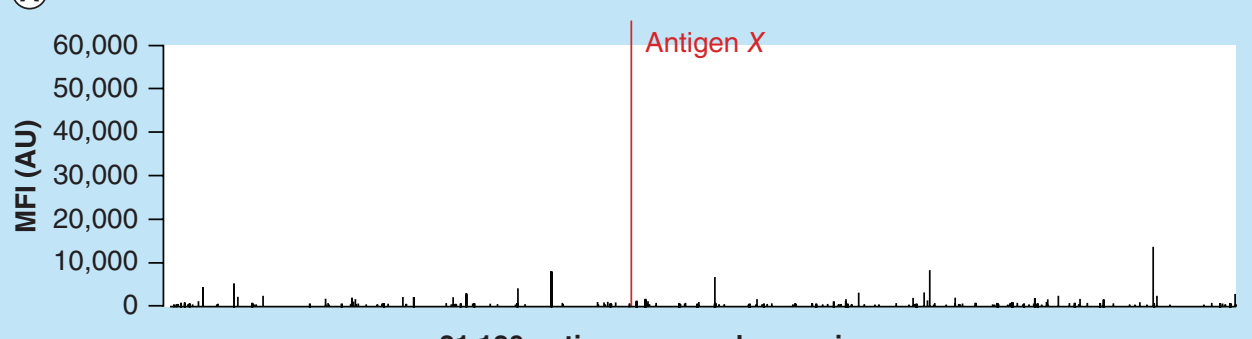

21,120 antigens on a planar microarray

(B)

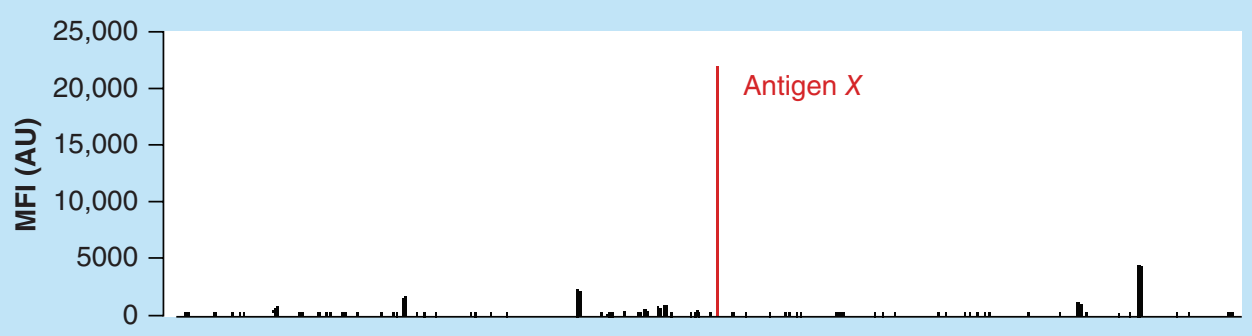

384 selected antigens in a bead-based array

Figure 6. Cross-platform technical verification of plasma IgG reactivity towards an antigen.

geted studies focus on describing the mechanisms and different phenotypes associated with the occurrence of autoantibodies against certain groups of proteins, such as cytokines: arrays of a large panel of cytokines, chemokines and other serum factors were utilized by Price et al. to investigate anticytokine autoantibodies in systemic lupus erythematosus [103] and by Rosenberg et al. for profiling anticytokine autoantibodies in a diverse set of patients with immunodeficiencies [110,111].

There were also several nontargeted approaches exploring the autoantibody repertoire in various diseases. Adopting the strategy originally described by Zhu et al. [12], arrays with 1058 full-length liver proteins were generated by $\mathrm{Hu}$ et al. [112], which were later extended to contain a total of 5011 human proteins and utilized in the context of autoimmune hepatitis [113]. By using arrays produced with the same strategy, Hu et al. utilized the arrays hosting 16,368 yeast-expressed human proteins [39] for profiling the serum and cerebrospinal fluid autoantibody repertoire in neuropsychiatric lupus [114]. Similarly, Hudson et al. utilized arrays with 5005 full-length human proteins to identify tumor-associated antigens within ovarian cancer [115]. The strategy of utilizing human fetal brain cDNA expression libraries to generate antigen arrays, originally described by Lueking et al. [115], was also applied in the context of dilated cardiomyopathy [116] and the autoimmune condition alopecia areata [117], where arrays with 37,200 redundant, recombinant human proteins were utilized. This setup, later commercialized by Protagen Diagnostics, and containing 3101 proteins or protein fragments was utilized within multiple sclerosis for autoantibody profiling in cerebrospinal fluid [118].

The previous work by Ayoglu et al. also exemplifies the hypothesis-free application of in-house generated antigen arrays, where a total of 11,520 human protein fragments representing 7644 protein-encoding genes were utilized for autoantibody profiling in a multiple sclerosis-related serum sample collection [23]. The more targeted follow-up work of this study recently led to the identification of the ion channel protein anoctamin 2 (ANO2) as an autoimmune target in multiple sclerosis, which might contribute to the characterization of a subgroup of MS patients. [119]. This strategy was also used for profiling the serum autoantibody repertoire within osteoarthritis [120], as well as adapted for profiling of autoantibody repertoires in bronchoalveolar lavage samples in the context of sarcoidosis [121]. These studies also demonstrate the utility of bead-based antigen arrays for autoantibody profiling in large sample collections.

Within the last few years, the majority of the nontargeted autoantibody profiling applications have utilized the commercial ProtoArray ${ }^{\circledR}$ platform. It has been used in a broad spectrum of diseases, including chronic renal disease [122] and renal transplantation [123]; hematological disorders [124] and autoimmune condi- 
tions such as rheumatoid arthritis [125], inflammatory bowel disease [126], Type-1 diabetes [127], Meniere's disease [128] and primary Sjögren's syndrome [129], where all the mentioned studies analyzed blood-derived samples except the latter one demonstrating the analysis of saliva samples. Targets identified by these and similar unbiased screening approaches contribute significantly for the molecular characterization of clinical phenotypes and manifestations of autoimmune diseases. For instance, utilizing the ProtoArray platform, Landegren $e t$ al. identified the enzyme transglutaminase 4 (TGM4) as a male-specific prostate autoantigen in autoimmune polyendocrine syndrome 1 (APS1), which was linked to the infertility component in male APS1 patients [130]. Within cancer field, ProtoArray has been used to identify tumor associated antigens in the context of colorectal cancer [131], bladder cancer [132] and ovarian and pancreatic cancer [133]. While these cancer-oriented studies focused on analysis of serum samples, Gunawardana et al. analyzed ascites fluid in the context of ovarian cancer [134]. ProtoArray has also been utilized for serum autoantibody profiling in neurological diseases such as Alzheimer's disease [135], Parkinson's disease [136] and amyotrophic lateral sclerosis [137], whereas Querol et al. analyzed cerebrospinal fluid in the context of multiple sclerosis [138]. While these studies reported disease-associated autoantibody reactivities, Nagele et al. profiled serum samples from healthy individuals and highlighted that $\operatorname{IgG}$ autoantibodies are ubiquitous in serum [139].

Antigen arrays generated by utilizing the in situ NAPPA strategy have been also frequently implemented for recent autoantibody profiling applications. The first studies utilizing NAPPA had a focus on analysis of serum autoantibodies within breast cancer $[140,141]$. More recently, in addition to other cancer types such as ovarian cancer [142], NAPPA has been utilized in the context of osteoarthritis [120] and various autoimmune conditions, including Type 1 diabetes [143], anklosing spondylitis [144] and juvenile arthritis [145], where the latter study also demonstrated the analysis of synovial fluid samples on the NAPPA platform.

Once targets of disease-associated autoantibodies are identified, peptide arrays allow for a fine-mapping of the epitopes of autoantibodies at a single amino acid resolution, that have been identified using protein array platforms. The utility of such high-density peptide arrays for autoantibody profiling applications has been demonstrated, for example, in the context of systemic lupus erythematosus $[52,146]$ and multiple sclerosis $[147,148]$.

Besides protein and peptide arrays, there are also examples of phage arrays which have been applied mostly within the cancer field for the identifica- tion of targets of tumor-specific autoantibodies. This approach combines the phage display technology with array technology. As described, for example, by Cekaite et al or Chatterjee et al., a cDNA library is constructed from mRNA isolated from cancer tissue and the cDNA library is inserted into a phage vector to generate cDNA phage-display library [149,150]. After several rounds of affinity maturation, the library is enriched for page clones reacting, for example, with serum from patients. The library of enriched clones is immobilized on solid supports to create phage arrays for further analysis of sample collections. This method has been applied for autoantibody profiling in various cancer types, such as breast cancer [151], prostate cancer [152], lung cancer [153,154], ovarian cancer [155] and colorectal cancer [156], as well as in some autoimmune conditions such as celiac disease [157].

In addition to the use of antigen arrays for identification of autoimmune targets, Papp et al. demonstrated for the first time that antigen arrays can also be utilized for a parallel measurement antigen-specific serum complement activation by detecting the deposited complement C3 fragments on antigen array surfaces $[66,158,159]$. Analysis of the complement activating property of autoantibodies is a valuable measure of the pathogenic potential of autoantibodies leading to inflammatory tissue damage. Thus it represents a powerful tool to evaluate the disease activity in a wide spectrum of systemic autoimmune diseases [160,161], such as rheumatoid arthritis, systemic lupus erythematosus, antineutrophil cytoplasmic autoantibody (ANCA)-associated vasculitides, systemic sclerosis, antiphospholipid antibody syndrome or primary Sjögren's syndrome. Assessment of complement-activating properties of autoantibodies, as well as their immunoglobulin classes, aims to generate more immune function-related information on antigen-arrays. This strategy, reviewed in more depth by Prechl et al. [162] was applied, for example, in the context of systemic lupus erythematosus [163]. While the originally described strategy by Papp et al. and later applications utilized planar arrays, the study by Ayoglu et al. [67] implemented this strategy further on bead-based antigen arrays for high-throughput profiling of samples.

\section{Conclusion \& future perspective}

As we discussed in this review, antigen arrays are not only tools to investigate limited sets of preselected proteins. They can rather serve as discovery tools to identify novel targets of disease-related autoantibodies in various disease conditions. We envision that antigen arrays will continue to be explored and exploited in the near future, as there is a remaining need to unravel the characteristics of autoantigens and the role and contri- 
bution of autoantibodies to health and disease. Therefore, antigen arrays are and will be very valuable tools for us to learn more about the autoantibody repertoires in different diseases, as well as the natural autoantibody repertoire in healthy individuals, which, in turn, might aim to translate findings of basic research into clinical practice and improved health outcomes.

Arrays composed of full-length proteins, protein fragments or peptides are currently all needed and should be utilized more to increase the understanding about the autoantibody repertoire in body fluid samples. Generating more information in more studies and disease areas will help to clarify the relevance and clinical value of each type of antigens, as well as the relevance of analysis of autoantibodies directed against continuous or discontinuous epitopes. Studies utilizing arrays with an unbiased content and of whole-proteome coverage can provide a particularly valuable starting point to unravel the common features of autoantigens being recognized in body fluid samples both in the context of diseases, as well as in health.

In near future, it will not only be about what the autoantibodies are binding to but also what kind of autoantibodies are binding to the self-proteins. More systematic studies shifting the focus to differences in immunoglobulin class frequencies might provide additional clues about whether certain set of antigens sharing certain features related to, for example, structure or localization co-determine the antibody class, thus the effector functions such as complement activation. As we highlighted here, identification of interesting autoantibody targets on antigen arrays should be followed by extensive technical verification stages. We also believe that bead-based arrays should be acknowledged more as an essential part of the antigen array-based biomarker investigations in the near future, as they allow to screen many more samples at a time in a straightforward manner, thus allowing for an effective validation of findings in extended sample collections. In terms of technical developments, analytical sensitivity of antigen arrays will be improved, as the interest for lower abundant autoantibodies will grow. Utilizing detection methods beyond the conventional fluorescence-based strategies and experimenting with more novel label-free or labelbased detection technologies is an area still open for development of new assay concepts on antigen arrays.

\section{Author contributions}

B Ayoglu outlined the subject of the review, searched for and interpreted the literature and wrote the manuscript with contributions from JM Schwenk and P Nilsson.

\section{Financial \& competing interests disclosure}

This work was supported by the ProNova VINN Excellence Centre for Protein Technology (VINNOVA, Swedish Governmental Agency for Innovation Systems) and by grants from SciLifeLab Stockholm and the KTH Center for Applied Proteomics funded by the Erling-Persson Family Foundation. B Ayoglu is supported by the Wallenberg Foundation Postdoctoral Scholarship Program. The authors have no other relevant affiliations or financial involvement with any organization or entity with a financial interest in or financial conflict with the subject matter or materials discussed in the manuscript apart from those disclosed.

No writing assistance was utilized in the production of this manuscript.

\section{Open access}

This work is licensed under the Attribution-NonCommercialNoDerivatives 4.0 Unported License. To view a copy of this license, visit http://creativecommons.org/licenses/by-nc-nd/4.0/

Executive summary

- Autoantibodies are increasingly interesting to be incorporated into diagnosis and classification criteria of various diseases including, but not limited to, autoimmune diseases.

- Antigen arrays offer the possibility to screen hundreds of body fluid samples for reactivity against hundreds to thousands of self-antigens at a time, consuming only tiny amounts of antigen and sample material.

- The generation of antigen resources, such as the Human Protein Atlas, and the availability of commercially available antigen array platforms are increasing and will accelerate the accessibility and use of antigen arrays.

- Within the recent years, antigen arrays in forms of protein, protein fragment or peptide arrays have been widely utilized for identification of novel autoimmune targets.

\section{References}

Papers of special note have been highlighted as: $\bullet$ of interest

1 Forslind K, Ahlmen M, Eberhardt K, Hafstrom I, Svensson B, Group BS. Prediction of radiological outcome in early rheumatoid arthritis in clinical practice: role of antibodies to citrullinated peptides (anti-CCP). Ann. Rheum. Dis. 63(9), 1090-1095 (2004)
2 Berglin E, Padyukov L, Sundin U et al. A combination of autoantibodies to cyclic citrullinated peptide (CCP) and HLA-DRB1 locus antigens is strongly associated with future onset of rheumatoid arthritis. Arthritis Res. Ther. 6(4), R303-R308 (2004).

3 Eriksson C, Kokkonen H, Johansson M, Hallmans G, Wadell G, Rantapaa-Dahlqvist S. Autoantibodies predate 
the onset of systemic lupus erythematosus in northern Sweden. Arthritis Res. Ther. 13(1), R30 (2011).

4 Jonsson R, Theander E, Sjöström B, Brokstad K, Henriksson G. Autoantibodies present before symptom onset in primary sjögren syndrome. JAMA 310(17), 1854-1855 (2013).

5 Zaenker P, Ziman MR. Serologic autoantibodies as diagnostic cancer biomarkers - a review. Cancer Epidemiol. Biomarkers Prev. 22(12), 2161-2181 (2013).

6 Garren H, Robinson WH, Krasulová E et al. Phase 2 trial of a DNA vaccine encoding myelin basic protein for multiple sclerosis. Ann. Neurol. 63(5), 611-620 (2008).

7 Damoiseaux J, Andrade LE, Fritzler MJ, Shoenfeld Y. Autoantibodies 2015: from diagnostic biomarkers toward prediction, prognosis and prevention. Autoimmun. Rev. 14(6), 555-563 (2015).

8 Feinberg JG. A 'Microspot' test for antigens and antibodies. Nature 192(4806), 985-986 (1961).

9 Ekins RP. Multi-analyte immunoassay. J. Pharm. Biomed. Anal. 7(2), 155-168 (1989).

10 Haab BB, Dunham MJ, Brown PO. Protein microarrays for highly parallel detection and quantitation of specific proteins and antibodies in complex solutions. Genome Biol. 2(2), RESEARCH0004 (2001).

11 Macbeath G, Schreiber SL. Printing proteins as microarrays for high-throughput function determination. Science 289(5485), 1760-1763 (2000).

12 Zhu H, Bilgin M, Bangham R et al. Global analysis of protein activities using proteome chips. Science 293(5537), 2101-2105 (2001).

13 Sutandy FXR, Qian J, Chen C-S, Zhu H. Overview of protein microarrays. Curr. Protoc. Protein Sci. Chapter 27, Unit 27.1 (2013).

14 Chandra H, Reddy PJ, Srivastava S. Protein microarrays and novel detection platforms. Expert Rev. Proteomics 8(1), 61-79 (2011).

15 Ray S, Mehta G, Srivastava S. Label-free detection techniques for protein microarrays: prospects, merits and challenges. Proteomics 10(4), 731-748 (2010).

16 Horan P, Wheeless L. Quantitative single cell analysis and sorting. Science 198(4313), 149-157 (1977).

17 Mchugh TM, Miner RC, Logan LH, Stites DP. Simultaneous detection of antibodies to cytomegalovirus and herpes simplex virus by using flow cytometry and a microsphere-based fluorescence immunoassay. J. Clin. Microbiol. 26(10), 1957-1961 (1988).

18 Fulton RJ, Mcdade RL, Smith PL, Kienker LJ, Kettman JR. Advanced multiplexed analysis with the FlowMetrix system. Clin. Chem. 43(9), 1749-1756 (1997).

19 Wu W, Slåstad H, De La Rosa Carrillo D et al. Antibody array analysis with label-based detection and resolution of protein size. Mol. Cell. Proteomics 8(2), 245-257 (2009).

20 Shovman O, Gilburd B, Barzilai $\mathrm{O}$ et al. Evaluation of the BioPlex 2200 ANA screen: analysis of 510 healthy subjects: incidence of natural/predictive autoantibodies. Ann. NY Acad. Sci. 1050, 380-388 (2005).
21 Venner AA, Ibañez D, Gladman DD et al. Comparison of three anti-dsDNA assays: performance and correlation with systemic lupus erythematosus disease activity. Clin. Biochem. 46(4-5), 317-320 (2013).

22 Martins TB, Litwin CM, Hill HR. Evaluation of a multiplex fluorescent microsphere immunoassay for the determination of Epstein-Barr virus serologic status. Am. J. Clin. Pathol. 129(1), 34-41 (2008).

23 Ayoglu B, Häggmark A, Khademi M et al. Autoantibody profiling in multiple sclerosis using arrays of human protein fragments. Mol. Cell. Proteomics 12(9), 2657-2672 (2013).

24 Zhu H, Qian J. Applications of functional protein microarrays in basic and clinical research. Adv. Genet. 79, 123-155 (2012).

25 He M, He Y, Luo Q, Wang M. From DNA to protein: no living cells required. Process Biochem. 46(3), 615-620 (2011).

Carlson ED, Gan R, Hodgman CE, Jewett MC. Cell-free protein synthesis: applications come of age. Biotechnol. Adv. 30(5), 1185-1194 (2012).

27 He M, Taussig MJ. DiscernArray technology: a cell-free method for the generation of protein arrays from PCR DNA. J. Immunol. Methods 274(1-2), 265-270 (2003).

28 He M, Taussig MJ. Single step generation of protein arrays from DNA by cell-free expression and in situ immobilisation (PISA method). Nucleic Acids Res. 29(15), E73-E73 (2001).

29 Angenendt P, Kreutzberger J, Glökler J, Hoheisel JD. Generation of high density protein microarrays by cell-free in situ expression of unpurified PCR products. Mol. Cell. Proteomics 5(9), 1658-1666 (2006).

30 Ramachandran N, Hainsworth E, Bhullar B et al. Selfassembling protein microarrays. Science 305(5680), 86-90 (2004).

31 Ramachandran N, Raphael JV, Hainsworth E et al. Nextgeneration high-density self-assembling functional protein arrays. Nat. Methods 5(6), 535-538 (2008).

32 Wong J, Sibani S, Lokko NN, Labaer J, Anderson KS. Rapid detection of antibodies in sera using multiplexed self-assembling bead arrays. J. Immunol. Methods 350(1-2), 171-182 (2009).

33 He M, Stoevesandt O, Palmer EA, Khan F, Ericsson O, Taussig MJ. Printing protein arrays from DNA arrays. Nat. Methods 5(2), 175-177 (2008).

34 Schmidt R, Cook EA, Kastelic D, Taussig MJ, Stoevesandt O. Optimised 'on demand' protein arraying from DNA by cell free expression with the 'DNA to Protein Array' (DAPA) technology. J. Proteomics 88 141-148 (2013).

35 Stoevesandt O, Vetter M, Kastelic D, Palmer EA, He M, Taussig MJ. Cell free expression put on the spot: advances in repeatable protein arraying from DNA (DAPA). N. Biotechnol. 28(3), 282-290 (2011).

36 Qiu J, Madoz-Gurpide J, Misek DE et al. Development of natural protein microarrays for diagnosing cancer based on an antibody response to tumor antigens. J. Proteome Res. 3(2), 261-267 (2004).

37 Chen C-S, Korobkova E, Chen $\mathrm{H}$ et al. A proteome chip approach reveals new DNA damage recognition activities in Escherichia coli. Nat. Methods 5(1), 69-74 (2008). 
38 Lueking A, Possling A, Huber O et al. A nonredundant human protein chip for antibody screening and serum profiling. Mol. Cell. Proteomics 2(12), 1342-1349 (2003).

39 Jeong JS, Jiang L, Albino E et al. Rapid identification of monospecific monoclonal antibodies using a human proteome microarray. Mol. Cell. Proteomics 11(6), O111.016253 (2012).

40 Uhlen M, Fagerberg L, Hallstrom BM et al. Tissuebased map of the human proteome. Science 347(6220), 1260419-1260419 (2015).

41 Sjöberg R, Sundberg M, Gundberg A et al. Validation of affinity reagents using antigen microarrays. $N$. Biotechnol. 29(5), 555-563 (2012)

42 Sjöberg R, Mattsson C, Andersson E et al. Exploration of high-density protein microarrays for antibody validation and autoimmunity profiling. N. Biotechnol. doi:10.1016/j. nbt.2015.09.002 (2015) (Epub ahead of print).

43 Geysen HM, Barteling SJ, Meloen RH. Small peptides induce antibodies with a sequence and structural requirement for binding antigen comparable to antibodies raised against the native protein. Proc. Natl Acad. Sci. USA 82(1), 178-182 (1985).

44 Frank R. Spot-synthesis: an easy technique for the positionally addressable, parallel chemical synthesis on a membrane support. Tetrahedron 48(42), 9217-9232 (1992).

45 Fodor SP, Read JL, Pirrung MC, Stryer L, Lu AT, Solas D. Light-directed, spatially addressable parallel chemical synthesis. Science 251(4995), 767-773 (1991).

46 Lipshutz RJ, Fodor SP, Gingeras TR, Lockhart DJ. High density synthetic oligonucleotide arrays. Nat. Genet. 21(Suppl. 1), 20-24 (1999).

47 Singh-Gasson S, Green RD, Yue Y et al. Maskless fabrication of light-directed oligonucleotide microarrays using a digital micromirror array. Nat. Biotechnol. 17(10), 974-978 (1999).

48 Shin D-S, Lee K-N, Yoo B-W et al. Automated maskless photolithography system for peptide microarray synthesis on a chip. J. Comb. Chem. 12(4), 463-471 (2010).

49 Buus S, Rockberg J, Forsström B, Nilsson P, Uhlén M, Schafer-Nielsen C. High-resolution mapping of linear antibody epitopes using ultrahigh-density peptide microarrays. Mol. Cell. Proteomics 11(12), 1790-1800 (2012).

50 Forsström B, Axnäs BB, Stengele K-P et al. Proteome-wide Epitope Mapping of Antibodies Using Ultra-dense Peptide Arrays. Mol. Cell. Proteomics 13(6), 1585-1597 (2014).

51 Gao X, Zhou X, Gulari E. Light directed massively parallel on-chip synthesis of peptide arrays with t-Boc chemistry. Proteomics 3(11), 2135-2141 (2003).

52 Price JV, Tangsombatvisit S, Xu G et al. On silico peptide microarrays for high-resolution mapping of antibody epitopes and diverse protein-protein interactions. Nat. Med. 18(9), 1434-1440 (2012).

53 Beyer M, Nesterov A, Block I et al. Combinatorial synthesis of peptide arrays onto a microchip. Science 318(5858), 1888 (2007).

54 Stadler V, Felgenhauer T, Beyer $\mathrm{M}$ et al. Combinatorial synthesis of peptide arrays with a laser printer. Angew. Chem. Int. Ed. Engl. 47(37), 7132-7135 (2008).
55 Katz C, Levy-Beladev L, Rotem-Bamberger S, Rito T, Rüdiger SGD, Friedler A. Studying protein-protein interactions using peptide arrays. Chem. Soc. Rev. 40(5), 2131-2145 (2011).

56 Balboni I, Limb C, Tenenbaum JD, Utz PJ. Evaluation of microarray surfaces and arraying parameters for autoantibody profiling. Proteomics 8(17), 3443-3449 (2008).

57 Wang J, Barker K, Steel J et al. A versatile protein microarray platform enabling antibody profiling against denatured proteins. Prot. Clin. Appl. 7(5-6), 378-383 (2013).

58 Legutki JB, Zhao Z-G, Greving M, Woodbury N, Johnston SA, Stafford P. Scalable high-density peptide arrays for comprehensive health monitoring. Nat. Commun. 5, 4785 (2014).

59 Stafford P, Cichacz Z, Woodbury NW, Johnston SA. Immunosignature system for diagnosis of cancer. Proc. Natl Acad. Sci. USA 111(30), E3072-E3080 (2014).

- Arrays of randomized-sequence peptides utilized for investigation of multi-disease aspect of serum antibody reactivities in various cancer types.

60 Reddy MM, Wilson R, Wilson J et al. Identification of candidate IgG biomarkers for Alzheimer's disease via combinatorial library screening. Cell 144(1), 132-142 (2011).

61 Rho J-H, Lampe PD. High-throughput screening for native autoantigen-autoantibody complexes using antibody microarrays. J. Proteome Res. 12(5), 2311-2320 (2013).

62 Prechl J, Papp K, Erdei A. Antigen microarrays: descriptive chemistry or functional immunomics? Trends Immunol. 31(4), 133-137 (2010).

63 Papp K, Szekeres Z, Erdei A, Prechl J. Two-dimensional immune profiles improve antigen microarray-based characterization of humoral immunity. Proteomics 8(14), 2840-2848 (2008).

64 Graham KL, Vaysberg M, Kuo A, Utz PJ. Autoantigen arrays for multiplex analysis of antibody isotypes. Proteomics 6(21), 5720-5724 (2006).

65 Hagedorn PH, Burton CM, Carlsen J et al. Chronic rejection of a lung transplant is characterized by a profile of specific autoantibodies. Immunology 130(3), 427-435 (2010).

66 Papp K, Végh P, Miklós K et al. Detection of complement activation on antigen microarrays generates functional antibody profiles and helps characterization of diseaseassociated changes of the antibody repertoire. J. Immunol. 181(11), 8162-8169 (2008).

67 Ayoglu B, Szarka E, Huber K et al. Bead arrays for antibody and complement profiling reveal joint contribution of antibody isotypes to C3 deposition. PLoS ONE 9(5), e96403 (2014).

68 Nei $T$, Urano $S$, Itoh $Y$ et al. Light chain $(\kappa / \lambda)$ ratio of GM-CSF autoantibodies is associated with disease severity in autoimmune pulmonary alveolar proteinosis. Clin. Immunol. 149(3, Part B), 357-364 (2013).

69 Hartmann M, Schrenk M, Döttinger A et al. Expanding assay dynamics: a combined competitive and direct assay system for the quantification of proteins in multiplexed immunoassays. Clin. Chem. 54(6), 956-963 (2008). 
70 Kattah MG, Alemi GR, Thibault DL, Balboni I, Utz PJ. A new two-color Fab labeling method for autoantigen protein microarrays. Nat. Methods 3(9), 745-751 (2006).

71 Mischak H, Critselis E, Hanash S, Gallagher WM, Vlahou A, Ioannidis JP. Epidemiologic design and analysis for proteomic studies: a primer on-omic technologies. Am. J. Epidemiol. 181(9), 635-647 (2015).

72 Zhou C, Simpson KL, Lancashire LJ et al. Statistical considerations of optimal study design for human plasma proteomics and biomarker discovery. J. Proteome Res. 11(4), 2103-2113 (2012).

73 Skates SJ, Gillette MA, Labaer J et al. Statistical design for biospecimen cohort size in proteomics-based biomarker discovery and verification studies. J. Proteome Res. 12(12), 5383-5394 (2013)

74 Wallstrom G, Anderson KS, Labaer J. Biomarker discovery for heterogeneous diseases. Cancer Epidemiol. Biomarkers Prev. 22(5), 747-755 (2013).

75 Ayoglu B, Häggmark A, Neiman M et al. Systematic antibody and antigen-based proteomic profiling with microarrays. Expert Rev. Mol. Diagn. 11(2), 219-234 (2011).

76 Leek JT, Scharpf RB, Bravo HC et al. Tackling the widespread and critical impact of batch effects in highthroughput data. Nat. Rev. Genet. 11(10), 733-739 (2010).

77 Van Den Berg RA, Hoefsloot HCJ, Westerhuis JA, Smilde AK, Van Der Werf MJ. Centering, scaling, and transformations: improving the biological information content of metabolomics data. BMC Genomics 7, 142 (2006).

78 Serneels S, Verdonck T. Principal component analysis for data containing outliers and missing elements. Computational Statistics \& Data Analysis 52(3), 1712-1727 (2008).

79 Shieh AD, Hung YS. Detecting outlier samples in microarray data. Stat. Appl. Genet. Mol. Biol. 8(1), 1-24 (2009).

80 Christin C, Hoefsloot HCJ, Smilde AK et al. A critical assessment of feature selection methods for biomarker discovery in clinical proteomics. Mol. Cell. Proteomics 12(1), 263-276 (2013).

81 Smit S, Hoefsloot HCJ, Smilde AK. Statistical data processing in clinical proteomics. J. Chromatogr. B 866(1-2), 77-88 (2008).

82 Huang DW, Sherman BT, Lempicki RA. Systematic and integrative analysis of large gene lists using DAVID bioinformatics resources. Nat. Protoc. 4(1), 44-57 (2009).

83 Franceschini A, Szklarczyk D, Frankild S et al. STRING v9.1: protein-protein interaction networks, with increased coverage and integration. Nucleic Acids Res. 41, D808-D815 (2013).

84 Füzery AK, Levin J, Chan MM, Chan DW. Translation of proteomic biomarkers into FDA approved cancer diagnostics: issues and challenges. Clin. Proteomics 10(1), 1-1 (2013).

85 Vigh-Conrad KA, Conrad DF, Preuss D. A protein allergen microarray detects specific IgE to pollen surface, cytoplasmic, and commercial allergen extracts. PLoS ONE 5(4), e10174 (2010).

86 Shreffler WG. Microarrayed recombinant allergens for diagnostic testing. J. Allergy Clin. Immun. 127(4), 843-849 (2011).
87 Vigil A, Davies DH, Felgner PL. Defining the humoral immune response to infectious agents using high-density protein microarrays. Future Microbiol. 5(2), 241-251 (2010).

Natesan M, Ulrich RG. Protein microarrays and biomarkers of infectious disease. Int. J. Mol. Sci. 11(12), 5165-5183 (2010).

89 Crompton PD, Kayala MA, Traore B et al. A prospective analysis of the $\mathrm{Ab}$ response to Plasmodium falciparum before and after a malaria season by protein microarray. Proc. Natl Acad. Sci. USA 107(15), 6958-6963 (2010).

90 Vigil A, Chen C, Jain A et al. Profiling the humoral immune response of acute and chronic $\mathrm{Q}$ fever by protein microarray. Mol. Cell. Proteomics 10(10), M110.006304 (2011).

91 Price JV, Jarrell JA, Furman D et al. Characterization of influenza vaccine immunogenicity using influenza antigen microarrays. PLoS ONE 8(5), e64555 (2013).

92 Driguez P, Doolan DL, Molina DM et al. Protein microarrays for parasite antigen discovery. Methods Mol. Biol. 1201, 221-233 (2015).

93 Joos TO, Schrenk M, Höpfl P et al. A microarray enzymelinked immunosorbent assay for autoimmune diagnostics. Electrophoresis 21(13), 2641-2650 (2000).

94 Robinson WH, Digennaro C, Hueber W et al. Autoantigen microarrays for multiplex characterization of autoantibody responses. Nat. Med. 8(3), 295-301 (2002).

95 Utz PJ. Protein arrays for studying blood cells and their secreted products. Immunol. Rev. 204 264-282 (2005).

96 Balboni I, Chan SM, Kattah M, Tenenbaum JD, Butte AJ, Utz PJ. Multiplexed protein array platforms for analysis of autoimmune diseases. Annu. Rev. Immunol. 24 391-418 (2006).

97 Fournel S, Muller S. Synthetic peptides in the diagnosis of systemic autoimmune diseases. Curr. Protein Pept. Sci. 4(4), 261-274 (2003).

98 Robinson WH, Steinman L, Utz PJ. Protein arrays for autoantibody profiling and fine-specificity mapping. Proteomics 3(11), 2077-2084 (2003).

99 Feng Y, Ke X, Ma R, Chen Y, Hu G, Liu F. Parallel detection of autoantibodies with microarrays in rheumatoid diseases. Clin. Chem. 50(2), 416-422 (2004).

100 Hueber W, Kidd BA, Tomooka BH et al. Antigen microarray profiling of autoantibodies in rheumatoid arthritis. Arthritis Rheum. 52(9), 2645-2655 (2005).

101 Fattal I, Shental N, Mevorach D et al. An antibody profile of systemic lupus erythematosus detected by antigen microarray. Immunology 130(3), 337-343 (2010).

102 Li Q-Z, Zhen QL, Xie C et al. Identification of autoantibody clusters that best predict lupus disease activity using glomerular proteome arrays. J. Clin. Invest. 115(12), 3428-3439 (2005).

103 Price JV, Haddon DJ, Kemmer D et al. Protein microarray analysis reveals BAFF-binding autoantibodies in systemic lupus erythematosus. J. Clin. Invest. 123(12), 5135-5145 (2013).

104 Haddon DJ, Diep VK, Price JV, Limb C, Utz PJ, Balboni I. Autoantigen microarrays reveal autoantibodies associated with proliferative nephritis and active disease in pediatric 
systemic lupus erythematosus. Arthritis Res. Ther. 17(1), 162 (2015).

105 Balboni I, Niewold TB, Morgan G et al. Interferon- $\alpha$ induction and detection of anti-ro, anti-la, anti-sm, and anti-rnp autoantibodies by autoantigen microarray analysis in juvenile dermatomyositis. Arthritis Rheum. 65(9), 2424-2429 (2013).

106 Quintana FJ, Farez MF, Viglietta V et al. Antigen microarrays identify unique serum autoantibody signatures in clinical and pathologic subtypes of multiple sclerosis. Proc. Natl Acad. Sci. USA 105(48), 18889-18894 (2008).

107 Quintana FJF, Farez MFM, Izquierdo GG, Lucas MM, Cohen IRI, Weiner HLH. Antigen microarrays identify CNS-produced autoantibodies in RRMS. Neurology 78(8), 532-539 (2012).

108 Britschgi M, Olin CE, Johns HT et al. Neuroprotective natural antibodies to assemblies of amyloidogenic peptides decrease with normal aging and advancing Alzheimer's disease. Proc. Natl Acad. Sci. USA 106(29), 12145-12150 (2009).

109 Gnjatic S, Wheeler C, Ebner M et al. Seromic analysis of antibody responses in non-small-cell lung cancer patients and healthy donors using conformational protein arrays. J. Immunol. Methods 341(1-2), 50-58 (2009).

110 Rosenberg JM, Price JV, Barcenas-Morales G et al. Protein microarrays identify disease-specific anti-cytokine autoantibody profiles in the landscape of immunodeficiency. J. Allergy Clin. Immunol. 137(1), 204-213 e203 (2016).

111 Rosenberg JM, Utz PJ. Protein microarrays: a new tool for the study of autoantibodies in immunodeficiency. Front. Immunol. 6, 138 (2015).

$112 \mathrm{Hu} \mathrm{S}$, Li Y, Liu G et al. A protein chip approach for highthroughput antigen identification and characterization. Proteomics 7(13), 2151-2161 (2007).

113 Song Q, Liu G, Hu S et al. Novel autoimmune hepatitisspecific autoantigens identified using protein microarray technology. J. Proteome Res. 9(1), 30-39 (2010).

$114 \mathrm{Hu} \mathrm{C}$, Huang W, Chen $\mathrm{H}$ et al. Autoantibody profiling on human proteome microarray for biomarker discovery in cerebrospinal fluid and sera of neuropsychiatric lupus. PLoS ONE 10(5), e0126643 (2015).

115 Hudson ME, Pozdnyakova I, Haines K, Mor G, Snyder M. Identification of differentially expressed proteins in ovarian cancer using high-density protein microarrays. Proc. Natl Acad. Sci. USA 104(44), 17494-17499 (2007).

116 Horn S, Lueking A, Murphy D et al. Profiling humoral autoimmune repertoire of dilated cardiomyopathy (DCM) patients and development of a disease-associated protein chip. Proteomics 6(2), 605-613 (2006).

117 Lueking A, Huber O, Wirths C et al. Profiling of alopecia areata autoantigens based on protein microarray technology. Mol. Cell. Proteomics 4(9), 1382-1390 (2005).

118 Beyer NH, Lueking A, Kowald A, Frederiksen JL, Heegaard $\mathrm{NH}$. Investigation of autoantibody profiles for cerebrospinal fluid biomarker discovery in patients with relapsingremitting multiple sclerosis. J. Neuroimmunol. 242(1-2), 7-7 (2012).
119 Ayoglu B, Mitsios N, Kockum I et al. Anoctamin 2 identified as an autoimmune target in multiple sclerosis. Proc. Natl Acad. Sci. USA 113(8), 2188-2193 (2016).

- Example study illustrating the potential of nontargeted serum autoantibody profiling approach within multiple sclerosis using protein fragment arrays.

120 Henjes F, Lourido LA, Ruiz-Romero C et al. Analysis of autoantibody profiles in osteoarthritis using comprehensive protein array concepts. J. Proteome Res. 13(11), 5218-5229 (2014).

121 Häggmark A, Hamsten C, Wiklundh E et al. Proteomic profiling reveals autoimmune targets in sarcoidosis. Am. J. Respir. Crit. Care Med. 191(5), 574-583 (2015).

122 Butte AJ, Sigdel TK, Wadia PP, Miklos DB, Sarwal MM. Protein microarrays discover angiotensinogen and PRKRIP1 as novel targets for autoantibodies in chronic renal disease. Mol. Cell. Proteomics 10(3), M110.000497 (2011).

123 Li L, Wadia P, Chen R et al. Identifying compartmentspecific non-HLA targets after renal transplantation by integrating transcriptome and "antibodyome" measures. Proc. Natl Acad. Sci. USA 106(11), 4148-4153 (2009).

124 Mias GI, Chen R, Zhang Y et al. Specific plasma autoantibody reactivity in myelodysplastic syndromes. Sci. Rep. 3, 3311 (2013).

125 Auger I, Balandraud N, Rak J, Lambert N, Martin M, Roudier J. New autoantigens in rheumatoid arthritis (RA): screening 8268 protein arrays with sera from patients with RA. Ann. Rheum. Dis. 68(4), 591-594 (2009).

126 Vermeulen N, De Béeck KO, Vermeire $S$ et al. Identification of a novel autoantigen in inflammatory bowel disease by protein microarray. Inflamm. Bowel Dis. 17(6), 1291-1300 (2011).

127 Koo BK, Chae S, Kim KM et al. Identification of novel autoantibodies in Type 1 diabetic patients using a highdensity protein microarray. Diabetes 63(9), 3022-3032 (2014).

128 Kim SH, Kim JY, Lee HJ, Gi M, Kim BG, Choi JY. Autoimmunity as a candidate for the etiopathogenesis of meniere's disease: detection of autoimmune reactions and diagnostic biomarker candidate. PLoS ONE 9(10), e111039 (2014).

$129 \mathrm{Hu}$ S, Vissink A, Arellano M et al. Identification of autoantibody biomarkers for primary Sjögren's syndrome using protein microarrays. Proteomics 11(8), 1499-1507 (2011).

130 Landegren N, Sharon D, Shum AK et al. Transglutaminase 4 as a prostate autoantigen in male subfertility. Sci. Transl. Med. 7(292), 292ra101 (2015).

- Example study utilizing the commercial ProtoArray platform to identify new targets related to infertility in male autoimmune polyendocrine syndrome 1 (APS1) patients.

131 Babel I, Barderas R, Díaz-Uriarte R, Martínez-Torrecuadrada JL, Sanchez-Carbayo M, Casal JI. Identification of tumorassociated autoantigens for the diagnosis of colorectal cancer in serum using high density protein microarrays. Mol. Cell. Proteomics 8(10), 2382-2395 (2009). 
132 Orenes-Piñero E, Barderas R, Rico D et al. Serum and tissue profiling in bladder cancer combining protein and tissue arrays. J. Proteome Res. 9(1), 164-173 (2010).

133 Gnjatic S, Ritter E, Büchler MW et al. Seromic profiling of ovarian and pancreatic cancer. Proc. Natl Acad. Sci. USA 107(11), 5088-5093 (2010).

134 Gunawardana CG, Memari N, Diamandis EP. Identifying novel autoantibody signatures in ovarian cancer using high-density protein microarrays. Clin. Biochem. 42(4-5), 426-429 (2009).

135 Nagele E, Han M, Demarshall C, Belinka B, Nagele R. Diagnosis of Alzheimer's disease based on disease-specific autoantibody profiles in human sera. PLoS ONE 6(8), e23112 (2011).

136 Han M, Nagele E, Demarshall C, Acharya N, Nagele R. Diagnosis of Parkinson's disease based on disease-specific autoantibody profiles in human sera. PLoS ONE 7(2), e32383 (2012).

137 May C, Nordhoff E, Casjens S et al. Highly immunoreactive IgG antibodies directed against a set of twenty human proteins in the sera of patients with amyotrophic lateral sclerosis identified by protein array. PLoS ONE 9(2), e89596 (2014).

138 Querol L, Clark PL, Bailey MA et al. Protein array-based profiling of CSF identifies RBPJ as an autoantigen in multiple sclerosis. Neurology 81(11), 956-963 (2013).

139 Nagele EP, Han M, Acharya NK, Demarshall C, Kosciuk MC, Nagele RG. Natural IgG autoantibodies are abundant and ubiquitous in human sera, and their number is influenced by age, gender, and disease. PLoS ONE 8(4), e60726 (2013).

140 Anderson KS, Ramachandran N, Wong J et al. Application of protein microarrays for multiplexed detection of antibodies to tumor antigens in breast cancer. J. Proteome Res. 7(4), 1490-1499 (2008).

141 Anderson KS, Sibani S, Wallstrom G et al. Protein microarray signature of autoantibody biomarkers for the early detection of breast cancer. J. Proteome Res. 10 (1), 85-96 (2011).

142 Anderson KS, Cramer DW, Sibani S et al. Autoantibody signature for the serologic detection of ovarian cancer. J. Proteome Res. 14(1), 578-586 (2015).

- Example study using the NAPPA platform for the analysis of autoantibodies towards tumor-derived antigens in ovarian cancer.

143 Miersch S, Bian X, Wallstrom G et al. Serological autoantibody profiling of Type 1 diabetes by protein arrays. J. Proteomics 94 486-496 (2013).

144 Wright C, Sibani S, Trudgian D et al. Detection of multiple autoantibodies in patients with ankylosing spondylitis using nucleic acid programmable protein arrays. Mol. Cell. Proteomics 11(2), M9.00384 (2012).

145 Gibson DS, Qiu J, Mendoza EA, Barker K, Rooney ME, Labaer J. Circulating and synovial antibody profiling of juvenile arthritis patients by nucleic acid programmable protein arrays. Arthritis Res. Ther. 14(2), R77 (2012).

146 Haddon DJ, Jarrell JA, Diep VK et al. Mapping epitopes of U1-70K autoantibodies at single-amino acid resolution. Autoimmunity 48(8), 513-523 (2015).
- Example study demonstrating the utility of peptide arrays for fine-mapping of autoantibody epitopes.

147 Hecker M, Fitzner B, Wendt M et al. High-density peptide microarray analysis of IgG autoantibody reactivities in serum and cerebrospinal fluid of multiple sclerosis patients. Mol. Cell. Proteomics doi:10.1074/mcp.M115.051664 (2016).

148 Hecker M, Lorenz P, Steinbeck F et al. Computational analysis of high-density peptide microarray data with application from systemic sclerosis to multiple sclerosis. Autoimmun. Rev. 11(3), 180-190 (2012).

149 Cekaite L, Hovig E, Sioud M. Monitoring B Cell Response to immunoselected phage-displayed peptides by microarrays. Methods Mol. Biol. 524, 273-285 (2009).

150 Chatterjee M, Wojciechowski J, Tainsky MA. Discovery of antibody biomarkers using protein microarrays of tumor antigens cloned in high throughput. Methods Mol. Biol. 520, 21-38 (2009).

151 Cekaite L, Haug O, Myklebost O et al. Analysis of the humoral immune response to immunoselected phagedisplayed peptides by a microarray-based method. Proteomics 4(9), 2572-2582 (2004).

152 Wang X, Yu J, Sreekumar A et al. Autoantibody signatures in prostate cancer. N. Engl. J. Med. 353(12), 1224 (2005).

153 Chen G, Wang X, Yu J et al. Autoantibody profiles reveal ubiquilin 1 as a humoral immune response target in lung adenocarcinoma. Cancer Res. 67(7), 3461-3467 (2007).

154 Zhong L, Hidalgo GE, Stromberg AJ, Khattar NH, Jett JR, Hirschowitz EA. Using protein microarray as a diagnostic assay for non-small-cell lung cancer. Am. J. Respir. Crit. Care Med. 172(10), 1308-1314 (2005).

155 Chatterjee M. Diagnostic markers of ovarian cancer by highthroughput antigen cloning and detection on arrays. Cancer Res. 66(2), 1181-1190 (2006).

156 Babel I, Barderas R, Diaz-Uriarte R et al. Identification of MST1/STK4 and SULF1 proteins as autoantibody targets for the diagnosis of colorectal cancer by using phage microarrays. Molecular \& Cellular Proteomics: MCP 10(3), M110.001784-M001110.001784 (2011).

157 D'Angelo S, Mignone F, Deantonio C et al. Profiling celiac disease antibody repertoire. Clin. Immunol. 148(1), 99-109 (2013).

158 Papp K, Szekeres Z, Terényi N, Isaák A, Erdei A, Prechl J. On-chip complement activation adds an extra dimension to antigen microarrays. Mol. Cell. Proteomics 6(1), 133-140 (2007).

- First description of the use of antigen arrays for a multiplex analysis of antigen-specific complement activation in serum.

159 Papp K, Végh P, Hóbor R, Erdei A, Prechl J. Characterization of factors influencing on-chip complement activation to optimize parallel measurement of antibody and complement proteins on antigen microarrays. J. Immunol. Methods 375(1-2), 75-83 (2012).

160 Chen M, Daha MR, Kallenberg CG. The complement system in systemic autoimmune disease. J. Autoimmun. 34(3), J276-J286 (2010).

161 Ballanti E, Perricone C, Greco E et al. Complement and autoimmunity. Immunol. Res. 56(2-3), 477-491 (2013). 
162 Prechl J, Szittner Z, Papp K. Complementing antibody profiles: assessing antibody function on antigen microarrays. Immunol. Lett. 143(1), 101-105 (2012).
163 Papp K, Végh P, Hóbor R et al. Immune complex signatures of patients with active and inactive SLE revealed by multiplex protein binding analysis on antigen microarrays. PLOS ONE 7(9), e44824 (2012) 